OPEN ACCESS

Edited by: Shawn Mikula,

Max Planck Institute of Neurobiology (MPG), Germany

Reviewed by:

Giorgio Innocenti, Karolinska Institute (KI), Sweden Angus M. Brown, University of Nottingham, United Kingdom

*Correspondence: Julien Cohen-Adad jcohen@polymtl.ca

Received: 15 September 2017 Accepted: 13 December 2017 Published: 22 December 2017

Citation:

Saliani A, Perraud B, Duval T, Stikov N, Rossignol $S$ and Cohen-Adad $J$ (2017) Axon and Myelin Morphology in Animal and Human Spinal Cord.

Front. Neuroanat. 11:129. doi: 10.3389/fnana.2017.00129

\section{Axon and Myelin Morphology in Animal and Human Spinal Cord}

\author{
Ariane Saliani ${ }^{1}$, Blanche Perraud ${ }^{1}$, Tanguy Duval ${ }^{1}$, Nikola Stikov ${ }^{1,2}$, Serge Rossignol ${ }^{3}$ and \\ Julien Cohen-Adad ${ }^{1,4 *}$
}

${ }^{1}$ NeuroPoly Lab, Institute of Biomedical Engineering, Polytechnique Montreal, Montreal, QC, Canada, ${ }^{2}$ Montreal Heart Institute, Montreal, QC, Canada, ${ }^{3}$ Groupe de Recherche sur le Système Nerveux Central, Department of Neuroscience, Faculty of Medicine, Université de Montréal, Montreal, QC, Canada, ${ }^{4}$ Functionnal Neuroimaging Unit, Centre de Recherche de l'Institut Universitaire de Gériatrie de Montréal, Université de Montréal, Montreal, QC, Canada

Characterizing precisely the microstructure of axons, their density, size and myelination is of interest for the neuroscientific community, for example to help maximize the outcome of studies on white matter (WM) pathologies of the spinal cord (SC). The existence of a comprehensive and structured database of axonal measurements in healthy and disease models could help the validation of results obtained by different researchers. The purpose of this article is to provide such a database of healthy SC WM, to discuss the potential sources of variability and to suggest avenues for robust and accurate quantification of axon morphometry based on novel acquisition and processing techniques. The article is organized in three sections. The first section reviews morphometric results across species according to range of densities and counts of myelinated axons, axon diameter and myelin thickness, and characteristics of unmyelinated axons in different regions. The second section discusses the sources of variability across studies, such as age, sex, spinal pathways, spinal levels, statistical power and terminology in regard to tracts and protocols. The third section presents new techniques and perspectives that could benefit histology studies. For example, coherent anti-stokes Raman spectroscopy (CARS) imaging can provide sub-micrometric resolution without the need for fixation and staining, while slide scanners and stitching algorithms can provide full cross-sectional area of SC. In combination with these acquisition techniques, automatic segmentation algorithms for delineating axons and myelin sheath can help provide large-scale statistics on axon morphometry.

Keywords: spinal cord, white matter, axons, myelin, histology, morphology

\section{INTRODUCTION}

Pathologies affecting the spinal cord (SC) could have diverse origins, from vascular diseases, cancer and trauma to neurodegenerative diseases such as multiple sclerosis. In many instances, there is limited knowledge about the actual pathophysiology of the disease, about the succession of neurotoxic events following a trauma (secondary injuries, Tator and Fehlings, 1991; Park et al., 2004), or even the precise vascularization depending on the tract. These issues make it difficult to assess accurately the extent of spinal damage.

SC research is commonly conducted in animal models to improve our understanding of a given pathology, its etiology and evolution, and to develop new therapies (Nout et al., 2012). Mice and rats, despite differences in the structural organization of the SC compared to humans, are one of 
the most commonly used animals for studying the SC due to the low cost, easy access, and well-established anatomical and functional analysis techniques (Nout et al., 2012; Lee and Lee, 2013; Silva et al., 2014). Cats have also been quite popular in electrophysiological and physiological studies of the SC since they have similar neuroanatomical features to those in humans with regard to SC architecture (Rossignol, 2006). In addition, the capacity of cats to regain locomotion after SCI makes them good candidates for SCI and remyelination studies (Rossignol, 2006; Lee and Lee, 2013; Silva et al., 2014). Lastly, monkeys are another model commonly used to deal with the significant differences in neuroanatomy existing between rats and primates (including humans). Some non-human primates are particularly interesting because of their bipedal locomotion (Nout et al., 2012). When possible, human tissue can be used for anatomical investigation, although several problems arise with the lack of perfusion and subsequent degradation of myelin sheaths in the SC. To maximize the outcome of these studies, it is essential to have access to normative values of axon morphometry (e.g., shape, density, degree of myelination) across various tracts and species. The existence of an exhaustive database recapitulating decades of work on the SC WM by experts in the field would be helpful in that regard.

In addition, novel non-invasive biomarkers based on quantitative magnetic resonance imaging have shown great potential for characterizing axonal damage, which is not easily detectable with conventional MRI. Although these advanced biomarkers are still limited by the spatial resolution MRI, they can provide average quantitative values of axon features within an MR voxel $\left(\sim 1 \mathrm{~mm}^{3}\right)$, such as axon diameter distribution (Assaf et al., 2008; Barazany et al., 2009; Huang et al., 2015) and myelin density (Laule et al., 2006; Stikov et al., 2011, 2015; Chen et al., 2013; Fjær et al., 2013; Duval et al., 2015). Applicable in the future for clinical diagnosis and drug development, these biomarkers are still under development and their use requires further validation, notably through comparison with histological data. The existence of an exhaustive database of axon microstructure would thus facilitate the validation of MRI metrics.

While many papers have been published on the characterization of WM axons in the SC, there is a need to summarize systematically those findings, compare them and discuss their possible limitations. The goals of this review article are therefore: (i) to systematize the existing knowledge about SC WM microstructure in different animal species, (ii) to discuss the potential sources of variability associated with these reports and (iii) to suggest optimal protocols and present novel strategies for large-scale histology of the SC. The functional aspects regarding the tracts are briefly mentioned in the conclusion.

\section{MORPHOMETRY OF SPINAL CORD MICROSTRUCTURE}

The SC is composed of several tracts (represented for humans in Figure 1), each with its particular role in the nervous system. Descending tracts [lateral motor system: corticospinal (CST) and rubrospinal tracts; medial motor system: reticulospinal and vestibulospinal tracts] are involved in motor control whereas ascending tracts (dorsal columns including fasciculus gracilis and cuneatus, spinothalamic, spinocerebellar, spinoreticular tracts) transmit sensory information including proprioception (Lawrence and Kuypers, 1968; Standring, 2008). Because all those tracts can be affected by pathology, it is important to characterize them individually.

As shown later on, the pyramidal tract has been the most studied one. Although the distinction between this tract and the corticospinal one is of particular importance (considering the termination of corticobulbar fibers in the brainstem) (Leenen et al., 1985; Brodal, 2010), terminology is sometimes imprecise thereby creating some confusion in the reporting (e.g., studies reporting microstructural information on the pyramidal tract at the cervical level).

\section{Range of Densities and Counts of Myelinated Axons in Different Tracts}

Table 1 reports densities and counts of myelinated fibers from various species (rats, cats, monkeys, humans). One point of uncertainty when creating the following table arose from the terminology used in some articles. Sometimes, when employing the word "fibers," authors did not explicitly mention if they were referring to myelinated fibers only or to all fibers (myelinated and unmyelinated). When applicable this distinction was indicated.

One notable observation emerging from this table is the variability in densities and counts from one specimen to another [e.g., density of 152,000 myelinated axons per $\mathrm{mm}^{2}$ vs. 125,000 (Biedenbach et al., 1986)], as well as from one study to the next [e.g., for the human pyramidal tract, Demyer (1959) counted 1,000,000 myelinated fibers against 49,000-67,000 for Wada et al. (2001)].

As a general trend, different fiber counts are associated with different spinal levels. For example, the pyramidal tract of the rat in the brainstem presents roughly between 90,000 and 140,000 fibers, depending on the study, whereas the CST at the cervical 2 level seems to be constituted by about 43,000 fibers (Leenen et al., 1985).

\section{Inter-species Variability in Fiber Counts}

It is proposed that from one species to the next some tracts gain in importance at the expense of others. The CST tract with its direct corticomotor connections is phylogenetically recent (Heffner and Masterton, 1983; Brodal, 2004; Schieber, 2007; Watson et al., 2009; Towe and Luschei, 2013), and is associated with a reduction of the rubrospinal tract in primates and in humans (Nathan and Smith, 1982; Gramsbergen, 2005; Schieber, 2007; Standring, 2008; Zelenin et al., 2010; de Oliveira-Souza, 2012). Indeed, for locomotion or movement, mammals (except humans) tend to employ more their non-corticospinal descending pathways (Schieber, 2007; Standring, 2008). This observation could be a first explanation for the larger number of fibers in the CST in monkeys than in rats (Nathan and Smith, 1982). A second explanation, likely complementary, would be the requirement of additional CST fibers due to the presence of direct corticomotor connections, leading to a larger CST (Uk and Al, 2006; Spence, 


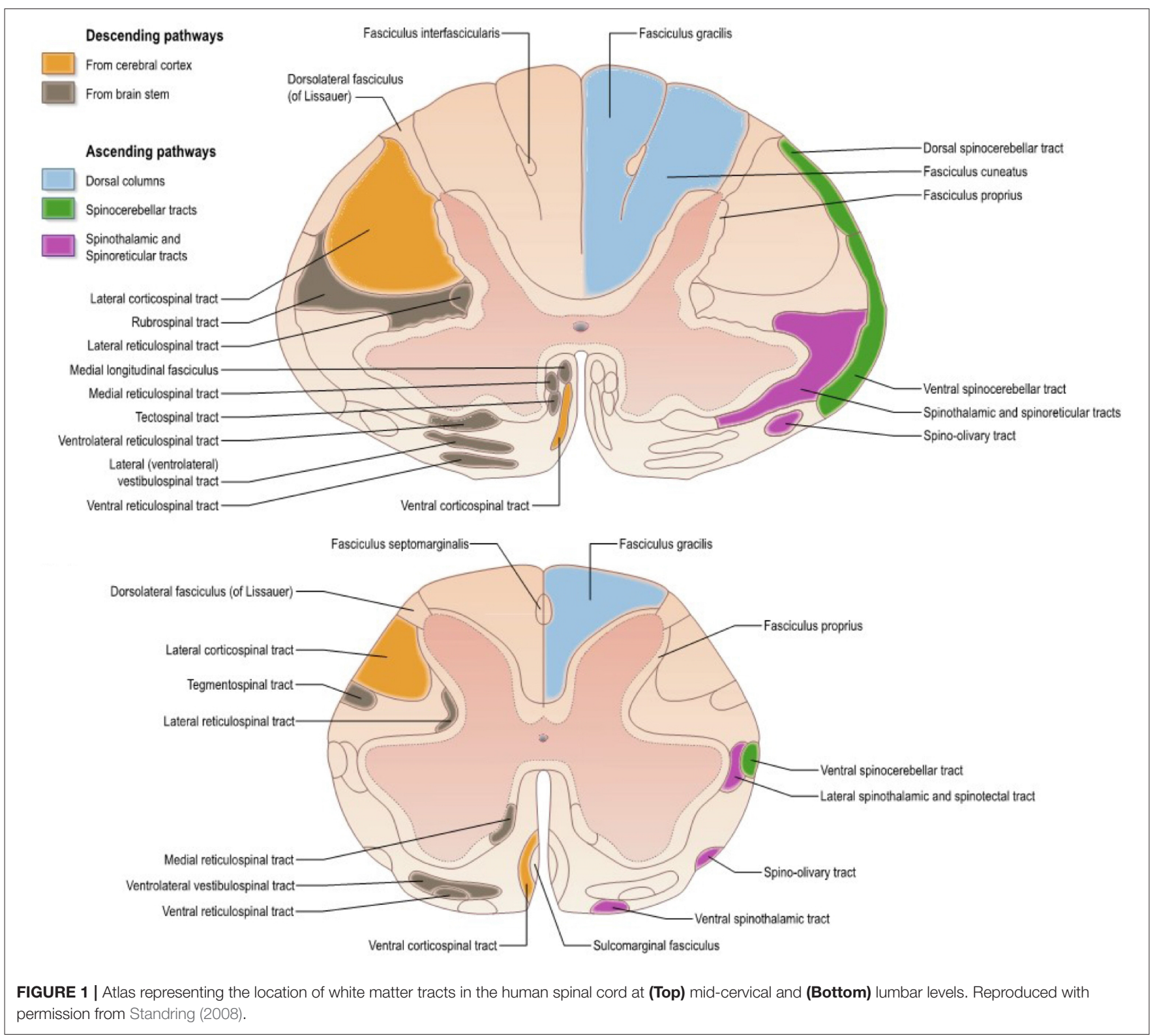

2009). Lastly, Heffner and Masterton (1975) pointed out a correlation between the length of the CST tract and the species' dexterity, which would imply longer tracts for primates. This would explain the inter-species variability in lower segments of the SC (e.g., sacral or lumbar levels) (Iwaniuk et al., 1999).

\section{Axon Diameter and Myelin Thickness across Species}

Axon diameter has been measured in several species. The numbers are reported in Table 2 along with the myelin sheath thickness. Note that in previously-published studies the word "fiber diameter" sometimes included the surrounding myelin sheath and sometimes not, without clear mention of it.

The average diameter in the pyramidal tract of the rat varies between $0.72 \mu \mathrm{m}$ (Leenen et al., 1985; Brösamle and Schwab,
2000) and $1.182 \mu \mathrm{m}$ (Harding and Towe, 1985). Variations could be due to different shrinkage (i.e., different protocols), interindividual differences, or due to whether the myelin sheath was included in the measurement. The distribution of calibers is broad (ranging from 0.1 to $6 \mu \mathrm{m}$ ) but more than $90 \%$ of axons are smaller than $1.5 \mu \mathrm{m}$. In the corticospinal tract, the average diameter is 0.72 and $0.68 \mu \mathrm{m}$ (respectively for the main and the ipsilateral ventral components) (Brösamle and Schwab, 2000).

In the cat, the only average axon diameter available is in the pyramidal tract, with a value of $1.98 \mu \mathrm{m}$ (Biedenbach et al., 1986). In this tract, diameters found were as low as $0.25 \mu \mathrm{m}$ and up to $23 \mu \mathrm{m}$ (Biedenbach et al., 1986), but the pyramidal tract is generally composed of thin fibers with the majority of axons smaller than $2 \mu \mathrm{m}$ (van Crevel and Verhaart, 1963; Biedenbach et al., 1986). Note that a maximal diameter of $23 \mu \mathrm{m}$ is quite high 
TABLE 1 | Counts and densities of myelinated fibers in nervous tissue (brainstem and spinal cord) in various species.

\begin{tabular}{|c|c|c|c|c|c|}
\hline Species & Anatomical location & $\begin{array}{l}\text { Density of myelinated fibers } \\
\text { per } \mathrm{mm}^{2}\end{array}$ & Number of myelinated fibers & Microscopy & References \\
\hline \multirow[t]{6}{*}{ Rat } & Pyramidal tract (brainstem) & & 91,000 & Electron & Leenen et al., 1982 \\
\hline & Pyramidal tract (spinal cervical 2 level) ${ }^{\mathrm{a}}$ & 483,300 & 43,000 & Electron & Leenen et al., 1985 \\
\hline & Sacral spinal cord ; Lateral funiculus & & 55,000 & Electron & Chung and Coggeshall, 1983 \\
\hline & Pyramidal tract & & 73,000 & Probably optical & Lassek and Rasmussen, 1940 \\
\hline & Pyramidal tract (cervical) & & $137,000^{a}$ & Optical & Brown, 1971 \\
\hline & Pyramidal tract (brainstem) & & $188,395-163,530$ & Electron & Harding and Towe, 1985 \\
\hline \multirow[t]{5}{*}{ Cat } & Pyramidal tract (brainstem) & & $186,000^{a}$ & & Lassek and Rasmussen, 1940 \\
\hline & Dorsal funiculus, sacral 2 spinal level & & $34,520 \pm 2,436$ & Electron & Chung et al., 1985 \\
\hline & Lateral funiculus, sacral 2 spinal level & & $159,774 \pm 7,762$ & Electron & Chung et al., 1985 \\
\hline & Ventral funiculus, sacral 2 spinal level & & $74,431 \pm 17,936$ & Electron & Chung et al., 1985 \\
\hline & Pyramidal tract (brainstem) & 143,291 & 356,583 & Electron & Biedenbach et al., 1986 \\
\hline \multirow[t]{3}{*}{ Monkey } & Pyramidal tract & & $554,000^{\mathrm{b}}$ & Optical & Lassek and Rasmussen, 1940 \\
\hline & Pyramidal tract & & $435,627^{b}$ & Optical & Russel and Demyer, 1961 \\
\hline & Pyramidal tract & & 594,000 & Electron & Firmin et al., 2014 \\
\hline \multirow[t]{2}{*}{ Human } & Pyramidal tract & & $1,087,200^{C}$ & & Demyer, 1959 \\
\hline & Pyramidal tract & $101,400^{b}$ & & & Towe, 1973 \\
\hline
\end{tabular}

a The terminology used is the authors'. Strictly speaking, the pyramidal tract is only in the midbrain and not in the SC.

${ }^{b}$ In some cases, there was uncertainty about whether the authors included only myelinated or both myelinated and unmyelinated fibers in their counts, as mentioned by this note.

${ }^{c}$ In other cases, the authors specified that their counts included unmyelinated fibers.

when comparing to the largest human myelinated fibers $[20 \mu \mathrm{m}$ with myelin sheath in the highest cases (Standring, 2008)], or to the results obtained for the monkey. One has to keep in mind the possibility of histological distortion or the possibility that authors included the myelin sheath in the measurement (this was not specified).

In the monkey, the average diameter in the pyramidal tract is $0.91 \mu \mathrm{m}$ (Firmin et al., 2014). Axon caliber distribution is broad, ranging from 0.04 to $9.48 \mu \mathrm{m}$. There is also a large presence of small fibers, with $52 \%$ of myelinated fibers presenting axons smaller than $1 \mu \mathrm{m}$ (Firmin et al., 2014). In addition, the tract is reported to be heavily myelinated (99\% of axons) (Firmin et al., 2014).

Axons of the pyramidal tract in humans were found to be as thin as $0.3 \mu \mathrm{m}$ (Graf and Schramm, 1983) and as large as $20 \mu \mathrm{m}$ (Verhaart, 1947), with a majority of thin fibers (about $84 \%$ ) smaller than $2 \mu \mathrm{m}$. This maximal diameter is high, even for human fibers, and possibly explained by inclusion of the myelin sheath. In the lateral CST, predominance of small fibers over large ones was shown to be more pronounced at cervical level 6 and lumbar level 4 than at thoracic level 7 (Terao et al., 1994). In a similar way, according to Ohnishi et al. (1976) in the fasciculus gracilis of humans, axon diameter is smaller at C3 than at T5.

\section{Comments on Previous Reports}

All studies seem to have characterized the pyramidal and corticospinal tracts as being mostly thin fibered with a unimodal distribution of axon diameter, regardless of the species. A few large fibers are scattered across the tract. There is a tendency for smaller species to have smaller axons, while larger species present higher maximal axonal diameters (Leenen et al., 1982; Biedenbach et al., 1986). To our knowledge, the spatial distribution of those large axons has not been studied. Rather significant discordance can be observed across studies on the same species when looking at numerical values: a trend in median axonal diameter is difficult to establish. 
TABLE 2 | Morphometric data on myelinated axons in nervous tissue obtained from various species.

\begin{tabular}{|c|c|c|c|c|c|c|c|}
\hline Species & Anatomical location & $\begin{array}{l}\text { Mean axonal } \\
\text { diameter }\end{array}$ & $\begin{array}{l}\text { Axonal diameter } \\
\text { range }\end{array}$ & $\begin{array}{l}\text { Diameter } \\
\text { distribution }\end{array}$ & $g$-ratio & $\begin{array}{l}\text { Myelin } \\
\text { thickness }\end{array}$ & References \\
\hline \multirow[t]{5}{*}{ Rat } & Pyramidal tract (brainstem) & $\begin{array}{l}0.80 \\
1.19 \text { (fibers) }\end{array}$ & $\begin{array}{l}0.10-4 \\
0.25-5 \text { (fibers) }\end{array}$ & $90 \%<1.5 \mu \mathrm{m}$ & & & Leenen et al., $1982^{b}$ \\
\hline & $\begin{array}{l}\text { Pyramidal tract (brainstem and } \\
\text { cervical } 2 \text { spinal level) }\end{array}$ & $\begin{array}{l}0.72 \\
1.08 \text { (fiber) }\end{array}$ & $\begin{array}{l}0.13-4.92 \\
0.25-6.03 \text { (fiber) }\end{array}$ & & 0.65 & 0.2 & Leenen et al., 1985 \\
\hline & Pyramidal tract (midbulbar) & $\begin{array}{l}1.054 \text { (fiber) } \\
1.182 \text { (fiber, with } \\
\text { shrinkage correction) }\end{array}$ & $\begin{array}{l}\text { Max. } \\
3.7 \text { and } 5.2 \\
\text { (fibers) }\end{array}$ & $\begin{array}{l}50 \%<1.2 \mu \mathrm{m} \\
\text { (fibers) }\end{array}$ & & & Harding and Towe, 1985ª \\
\hline & Corticospinal tract (cervical 2) & $\begin{array}{l}0.68 \text { (ipsilateral ventral) } \\
0.72 \text { (main) }\end{array}$ & & & & & Brösamle and Schwab, $2000^{a}$ \\
\hline & Corticospinal tract (cervical) & & $0.5-3$ & & & & Joosten and Gribnau, 1988ª \\
\hline \multirow[t]{3}{*}{ Cat } & Pyramidal tract (brainstem) & & $<10$ (fibers) & $\begin{array}{l}73 \% 0-2 \mu \mathrm{m} \\
20 \% 2-4 \mu \mathrm{m} \\
5 \% 4-6 \mu \mathrm{m} \\
2 \%>6 \mu \mathrm{m} \\
\text { (fibers) }\end{array}$ & & & $\begin{array}{l}\text { van Crevel and Verhaart, } \\
1963^{b}\end{array}$ \\
\hline & Pyramidal tract (brainstem) & $\begin{array}{l}1.98 \\
\text { (median: 1.60) }\end{array}$ & $0.25-23$ & $\begin{array}{l}>50 \%<2 \mu \mathrm{m} \\
1 \%>9 \mu \mathrm{m} \\
25 \% 0.5-1 \mu \mathrm{m} \\
20 \% 1-1.5 \mu \mathrm{m}\end{array}$ & & & Biedenbach et al., $1986^{a}$ \\
\hline & Fasciculus gracilis (cervical) & & $<1-15$ & $\begin{array}{l}97 \%<8 \mu \mathrm{m} \\
50 \% 2-5 \mu \mathrm{m}\end{array}$ & & & Thomas et al., 1984a \\
\hline \multirow[t]{2}{*}{ Monkey } & Pyramidal tract (brainstem) & & $0.4-6$ & & & & Ralston et al., 1987a \\
\hline & Pyramidal tract (brainstem) & $\begin{array}{l}0.91 \text { (median: 0.68) } \\
\text { Fiber: } 1.32 \text { (median: } \\
0.97 \text { ) }\end{array}$ & $0.04-9.48$ & $\begin{array}{l}52 \%<1 \mu \mathrm{m} \\
14 \%<0.5 \mu \mathrm{m}\end{array}$ & & & Firmin et al., $2014^{a}$ \\
\hline \multirow[t]{3}{*}{ Human } & Pyramidal tract (brainstem) & & & $\begin{array}{l}70 \%<1 \mu \mathrm{m} \\
84 \%<2 \mu \mathrm{m} \\
\text { (fibers) }\end{array}$ & & & $\begin{array}{l}\text { Lassek and Rasmussen, } \\
1940^{\mathrm{b}}\end{array}$ \\
\hline & Pyramidal tract (brainstem) & & $\begin{array}{l}1-20 \\
\text { (fibers) }\end{array}$ & $\begin{array}{l}90 \%>1 \mu \mathrm{m} \\
\text { (fibers) }\end{array}$ & & & Verhaart, $1947^{\mathrm{b}}$ \\
\hline & Pyramidal tract (brainstem) & & $\sim 0.3-10$ & $\begin{array}{l}88 \%<4 \mu \mathrm{m} \\
10.77 \% 4-10 \mu \mathrm{m} \\
1.4 \%>10 \mu \mathrm{m} \\
\text { (fibers) }\end{array}$ & $\begin{array}{c}0.6 \text { for axon < } \\
0.5 \mu \mathrm{m} \\
>0.6 \text { for axon } \\
>0.5 \mu \mathrm{m}\end{array}$ & & Terao et al., 1994ª \\
\hline
\end{tabular}

Studies marked with ${ }^{(a)}$ have been conducted through electron microscopy, the ones marked with ( ${ }^{b}$ ) have been conducted with optical microscopy.

If larger species have higher maximal diameters, they still present very thin axons thereby providing them with a broader range of axonal diameters. Since the largest fibers of the pyramidal tract represent only a small fraction of the fibers the median diameter does not change very much across species. It is possible that the majority of the "new" fibers (excluding the new larger ones) would be rather small fibers, leading to a stable median axonal diameter. There is therefore an interest in reporting the distribution and the median as opposed to only the mean axonal diameter.

The thickness of the myelin sheath is a parameter of interest in SC morphometry. One way to express it is through the $g$-ratio, which is defined as the ratio between the inner axonal diameter of the fiber to the external diameter or total diameter (including the myelin sheath). Conduction velocity of electrical impulse is maximal with a $g$-ratio of 0.6-0.7 (Rushton, 1951; Leenen et al., 1985; Johansen-Berg and Behrens, 2013). However, this is not a general rule. For instance, large axons seem to have higher g-ratio (Hildebrand and Hahn, 1978; Biedenbach et al., 1986; Johansen-Berg and Behrens, 2013). Furthermore, several studies have reported variations on the degree of myelination of axons presenting the same diameter, in rat and human tissue: for small axons the myelin thickness could vary by up to a factor 4 (Graf and Schramm, 1983; Harding and Towe, 1985).

\section{Importance of Fiber Circularity for Axonal Diameter Measures}

The form factor of a fiber (or eccentricity) is the ratio of the smallest to the largest diameter (Leenen et al., 1985). In the pyramidal tract of the rat this factor has been measured by Leenen et al. (1985) as 0.75 and 0.70 for myelinated axons, respectively with and without the myelin sheath. Accordingly, the fibers in the cat's pyramidal tract have been characterized by a small but consistent deviation from the circular shape (Biedenbach et al., 
1986). Furthermore, in this case, circularity was decreasing with increasing diameter.

Assuming that axons in the SC are perfectly circular, incorrect cutting will translate into elliptic profiles, and the measure of circularity may prove useful to quantify the extent of the distortion. This objective value of circularity would help the reader to control the degree of the histological bias in the reported morphometric values.

\section{Characteristics (Size, Density, Counts) of Unmyelinated Axons}

Since the 80 's, the presence of a high number of unmyelinated axons in the WM of the SC is often reported, particularly in cats and rats (Langford and Coggeshall, 1981; Leenen et al., 1982, 1985; Chung and Coggeshall, 1983; Chung et al., 1985; Harding and Towe, 1985).

\section{Range of Diameters}

The characteristics of unmyelinated fibers have been summarized for the rat, the cat and the monkey in Table 3.

In rats, the pyramidal tract contains unmyelinated axons with diameters between 0.05 and $1 \mu \mathrm{m}$, while the mean are around $0.16 \mu \mathrm{m}$ (Leenen et al., 1982).

In cats, the same tract presents unmyelinated axons with an average diameter of $0.18 \mu \mathrm{m}$, but ranging from 0.05 to $0.6 \mu \mathrm{m}$ (Thomas et al., 1984). On the other hand, one study reported that the CST at sacral 2 level seems to have slightly larger fibers (0.1-1 $\mu \mathrm{m})$ (Chung et al., 1985).

In monkeys, fibers are characterized by diameters ranging from 0.07 to $2.25 \mu \mathrm{m}$, much larger than in the other species (Ralston et al., 1987).

\section{Axonal Counts and Densities}

In a similar fashion to myelinated axons, the counts and densities of unmyelinated fibers have been summarized in Table 4, and similar inter-study variability can be observed. In the cat's pyramidal tract, some authors have found as few as 20,000 fibers against 47,000 for others (Thomas et al., 1984; Biedenbach et al., 1986). In addition, Thomas et al. (1984) also presented great inter-individual variability in their study since their counts ranged from 20,000 to 63,000 .

In rats, about $12 \%$ of the fibers in the CST seem to be unmyelinated (Brösamle and Schwab, 2000), as opposed to about $60 \%$ in the pyramidal tract (Ralston et al., 1987). In terms of numbers, the cervical portion of the CST of the rat presents only 35,000 fibers against 140,000 for the pyramidal tract at the medullary level (Leenen et al., 1982, 1985). This decrease is mainly due to corticobulbar projections terminating in the brainstem.

In cats, a similar proportion of umyelinated fibers can be found as $12 \%$ of the pyramidal tract is unmyelinated at the medullary level. However, in the tract of Lissaeur, this proportion reaches around $80 \%$ at mid-thoracic and lumbosacral levels. At sacral levels, Chung et al. (1985) shows that $45 \%$ of the SC WM is unmyelinated in the cat, a surprisingly high level of myelination. It has to be noted that a high concentration of unmyelinated fibers can be found at the tract of Lissaeur and in the dorsal funiculi, and that propriospinal fibers could also participate in this high unmyelinated count (Chung et al., 1979; Thomas et al., 1984; Biedenbach et al., 1986).

As opposed to those species, monkeys appear to present very few unmyelinated axons $(<1 \%)$ in the pyramidal tract (Ralston et al., 1987).

As can be expected, fibers count drops considerably from the medullary pyramids to the cervical levels of the CST: (Leenen et al., 1982, 1985). At a given spinal level, the type of tract also plays a role: for example in the cat, the lateral funiculus contains much more unmyelinated fibers $(125,000)$ than the ventral or dorsal ones (30,000 and 20,000) (Chung et al., 1985).

\section{Points of Importance Regarding Unmyelinated Axons Characteristics}

With the few numbers of studies on unmyelinated fibers morphometry, it is difficult to draw trends. Furthermore, studies have been conducted in the pyramids in the medulla oblongata, inducing a possible bias with the presence of corticobulbar fibers in the pyramidal tracts. Secondly, another bias could arise with a possible confusion between unmyelinated fibers

TABLE 3 | Morphometric data of unmyelinated fibers in nervous tissue (brainstem or spinal cord).

\begin{tabular}{|c|c|c|c|c|c|c|}
\hline Species & Tract & Anatomical level & $\begin{array}{l}\text { Axonal diameter } \\
\text { range }(\mu \mathrm{m})\end{array}$ & $\begin{array}{l}\text { Mean axonal } \\
\text { diameter }(\mu \mathrm{m})\end{array}$ & $\begin{array}{l}\text { Axonal diameter } \\
\text { distribution }(\mu \mathrm{m})\end{array}$ & References \\
\hline \multirow[t]{3}{*}{ Rat } & Pyramidal & Medullary pyramid & $0.05-1$ & 0.16 & & Leenen et al., 1982 \\
\hline & Corticospinal & Main component & $0.72-1.48$ & $0.72 \pm 0.05$ & & Brösamle and Schwab, 2000 \\
\hline & Corticospinal & Ipsilateral ventral & & $0.68 \pm 0.04$ & & Brösamle and Schwab, 2000 \\
\hline \multirow[t]{4}{*}{ Cat } & Lissauer & Thoracic and lumbar & & & & Chung et al., 1979 \\
\hline & Pyramidal & Medulla pyramid & $0.05-0.6$ & 0.18 & $\begin{array}{c}0.10-0.30=94 \% \\
0.01 \%>0.5\end{array}$ & Thomas et al., 1984 \\
\hline & Pyramidal & Sacral 2 & $0.1-1$ & & & Chung et al., 1985 \\
\hline & Pyramidal & Medullary pyramid & $0.05-0.6$ & 0.18 & & Biedenbach et al., 1986 \\
\hline Monkey & Pyramidal & Medullary pyramid & $0.07-2.25$ & & & Ralston et al., 1987 \\
\hline
\end{tabular}

All those studies have been conducted with electron microscopy. 
TABLE 4 | Counts and densities of unmyelinated fibers in brainstem and spinal cord.

\begin{tabular}{|c|c|c|c|c|c|}
\hline Species & Anatomical location & $\begin{array}{l}\text { Density of unmyelinated } \\
\text { fibers per } \mathrm{mm}^{2}\end{array}$ & $\begin{array}{l}\text { Number of unmyelinated } \\
\text { fibers }\end{array}$ & $\begin{array}{c}\text { Proportion of } \\
\text { unmyelinated fibers (\%) }\end{array}$ & References \\
\hline \multirow[t]{3}{*}{ Rat } & Pyramidal tract (brainstem) & 518,700 & 140,000 & & Leenen et al., 1985 \\
\hline & Pyramidal tract (brainstem) & & 133,000 & 12 & Leenen et al., 1982 \\
\hline & Pyramidal tract (cervical) & 396,200 & 35,000 & 13 & Leenen et al., 1985 \\
\hline \multirow[t]{8}{*}{ Cat } & Pyramidal tract & 20,768 & 47,645 & 12 & Biedenbach et al., 1986 \\
\hline & Pyramidal tract & 10,696 and 15,166 & $20,750-63,290$ & 8 and 15 & Thomas et al., 1984 \\
\hline & Dorsal funiculus, sacral 2 & & $8,488 \pm 845$ & 29 & Chung et al., 1985 \\
\hline & Dorsal funiculus, sacral 2 & & $19,559 \pm 1,465$ & 36 & Chung et al., 1985 \\
\hline & Lateral funiculus, sacral 2 & & $126,763 \pm 29,858$ & 44 & Chung et al., 1985 \\
\hline & Ventral funiculus, sacral 2 & & $32,182 \pm 6,587$ & 30 & Chung et al., 1985 \\
\hline & WM sacral 2 & & & 45 & Chung et al., 1985 \\
\hline & Tract of Lissauer, sacral 1 and sacral 3 & & 49,500 & 80 & Chung et al., 1979 \\
\hline
\end{tabular}

All those studies have been conducted with electron microscopy.

and glial processes therefore overestimating unmyelinated fibers counts (Ralston et al., 1987). Also note that dendrites can also be found in the WM (Ralston et al., 1987). Confusion of structure however remains unlikely considering that studies were accomplished with transmit electron microscopy (TEM), providing high resolution and hence easy identification of cell structures.

The available information would perhaps suggest a decrease in unmyelinated fibers in the CST along the phylogenetic tree. This reduction could be correlated with the use of distal muscles to accomplish fine tasks (Ralston et al., 1987), or as a compensatory mechanism for the longer distances. Another possibility, at lower level than the medulla, would be the presence of propriospinal fibers running along several levels of the SC (Chung et al., 1985). Lastly, those unmyelinated fibers may also be collaterals from myelinated projections and with the increase of direct corticomotor connections, the number of those collaterals may decrease in primates (Schieber, 2007). Nevertheless, further additional studies are required to confirm the variation in unmyelinated fibers and their identification.

\section{General Comments on Previous Literature Major Interest in the Pyramidal Tract and Corticospinal Tract}

Most studies on neuroanatomy have been conducted on the pyramidal tract. It is the most studied pathway in the CNS, although some articles focused more on the CST (Leenen et al., 1982; Brösamle and Schwab, 2000). This tract is heavily involved in the motor control of the body, even more so in primates and humans (Thomas et al., 1984; Brodal, 2010; Firmin et al., 2014). In addition to its important physiological role, the pyramidal tract is also appealing since it can be rather easily identified at the level of the medulla (Thomas et al., 1984). As for the other tracts, very little information is available: the fasciculus gracilis in the SC dorsal column is reported to contain predominantly small diameter axons, whereas other tracts such as the corticospinal in the lateral columns and the ventral columns contain a mixture of small and large diameter axons (Johansen-Berg and Behrens, 2013).

\section{Difficulty of Assessing the Type of Pathway}

Many studies rely on subjective approximate location of tracts based on previous atlas work and on the researcher's judgment, which necessarily adds uncertainty and bias. The variability in the location of the CST amongst species requires the use of an atlas established precisely for each particular species, at each spinal level (Leenen et al., 1985; Watson et al., 2009; Meurant, 2011; Watson and Harrison, 2012). Nevertheless, tract location and size could also be subject to inter-individual variability (Watson et al., 2009; Meurant, 2011). In addition, some tracts may overlap, such as the lateral vestibulospinal tract, the ventral spinothalamic tract and the rostral reticulospinal tract in the mouse (Figure 2). Lastly, the possible presence of ascending fibers in some tracts could also influence the analysis (Leenen et al., 1982, 1985; Thomas et al., 1984).

To be certain about the pathway observed, studies would require tracing methods in order to obtain a precise identification (e.g., di-I, dextran amines, Fluoro-Gold, PHA-L) (Köbbert et al., 2000; Reiner et al., 2000; Sparks et al., 2000; Vercelli et al., 2000; Altman and Bayer, 2001). The main drawback for tracing methods is the short penetration obtained in general (Sparks et al., 2000). Furthermore, with this technique tagging precisely the complete tract and preparing the tissue for observation can be complicated (e.g., washing out of diI during dehydration) (Köbbert et al., 2000; Reiner et al., 2000; Vercelli et al., 2000).

Some articles such as the one by Harding and Towe (1985) used a simpler method: they identified the pyramidal tract as the region presenting a high density of fine fibers, with only a few coarser fibers scattered throughout. To identify the border with the medial lemniscus, a large bundle of heavily myelinated ascending axons, the latter was characterized as composed of coarser fibers but they mentioned the difficulty of this technique in establishing a clear boarder. The efficacy of this protocol is indeed debatable, since the medial lemniscus covers the dorsal 

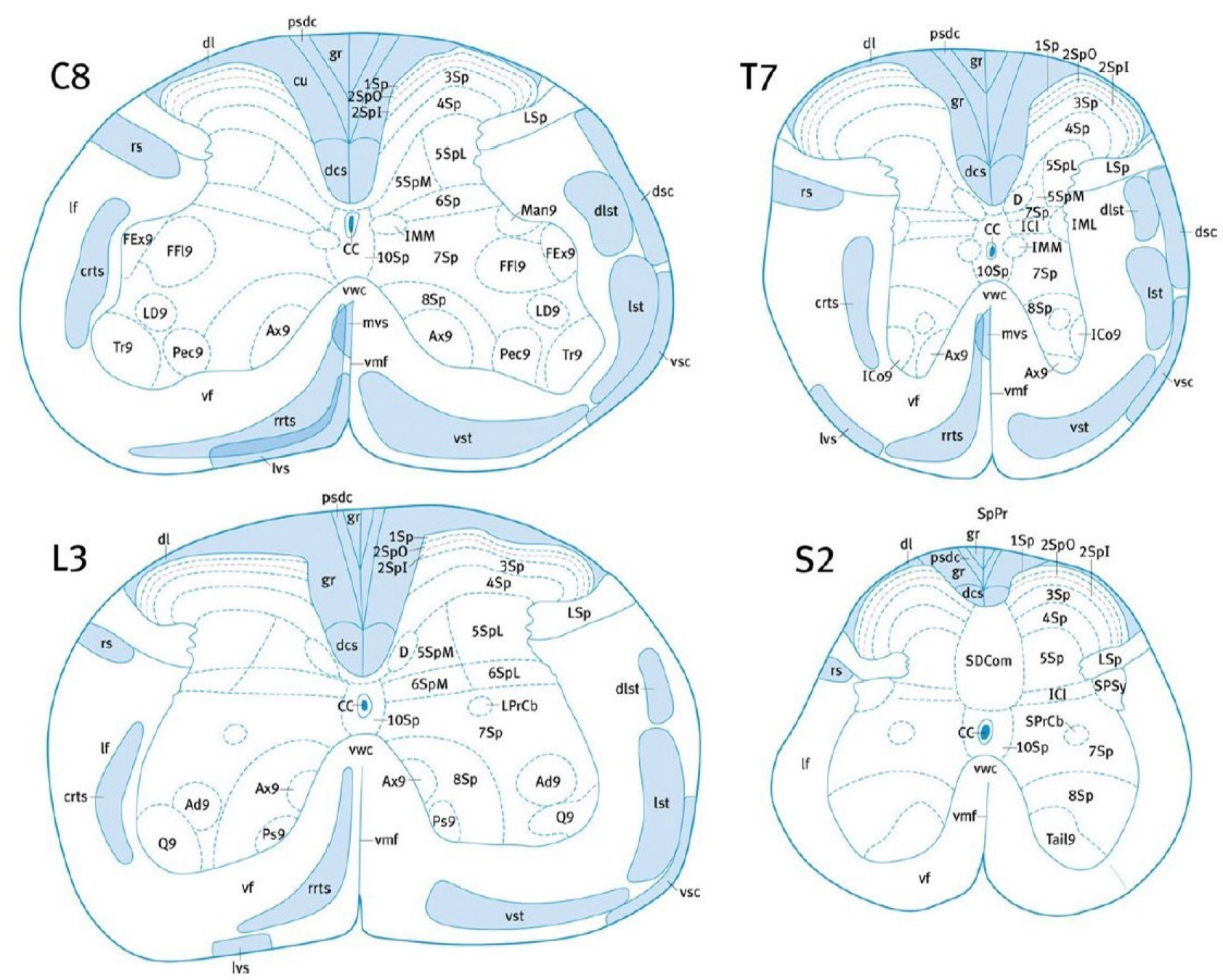

FIGURE 2 | Localization of the major white matter tracts of the mouse SC, at C8, T7, L3, and S2 levels. Adapted with permission from (Watson and Harrison, 2012). 1Sp, lamina 1; 2Spl, lamina 2 inner part; 2SpO, lamina 2 outer part; 3Sp, lamina 3; 7Sp, lamina 7; CC, central canal; crts, caudal reticulospinal tract; cu, cuneate fasciculus; dcs, dorsal corticospinal tract; dsc, dorsal spinocerebellar tract; dl, dorsolateral fasciculus; dlst, dorsolateral spinothalamic tract; gr, gracile fasciculus; IML, intermediolateral column; Ist, lateral spinothalamic tract; LSp, lateral spinal nucleus; Ivs, lateral vestibulospinal tract; mvs, medial vestibulospinal tract; pdsc, postsynaptic dorsal column pathway; rrts, rostral reticulospinal tract; rs, rubrospinal tract; SPSy, sacral parasympathic nucleus; vsc, ventral spinocerebellar tract; vst, ventral spinothalamic tract.

part of the pyramids (van Crevel and Verhaart, 1963; Biedenbach et al., 1986). For some tracts this technique could be applicable such as in rodents where the dorsal CST is rather well defined, bordered by the dorsal horns and presenting a clear difference in densities and axon diameter to the cuneatus, another tract also quite easy to identify (Hanaway et al., 1998; Standring, 2008). Yet, this technique is not applicable to all SC tracts (such as the rubrospinal pathway or the lateral corticospinal pathway) as it will be too imprecise (Standring, 2008). Other papers do not even mention their identification protocol, preventing readers to evaluate the biases that could exist.

A way to avoid the problem of assessing the pathway would be to do an analysis on a rougher compartmentalization of the SC, comparing or singling out wider regions of the SC. One could separate the SC in three blocs: dorsal, lateral and ventral in a similar fashion to Chung et al. (1985). The main drawback of this approach is that it does not bring precise information on the composition and exact morphology of each tract. On the other hand, this type of study would be very interesting for validation purposes, for example for new quantitative MRI studies.

Literature contains few microstructural studies on the WM of the SC and rather focuses on the pyramidal tract in the brainstem. Data on axonal morphometry in SC is therefore scarce, and the predominant interest toward the corticospinal tract is at the expense of other tracts. There is also very little data regarding myelin sheath thickness in the literature. Out of the microstructural studies published, a clear problem appears: the lack of homogeneity in the findings, whether across studies or in the same study. The next section addresses the potential sources of variability. 


\section{SOURCES OF VARIABILITY}

Different factors could explain the high intra- and inter-study variability described in the previous section. Taking them into consideration is important to be able to establish trends in morphometry. It is also important for injured SC morphometry as it could obscure effects of the pathologies. For example, body weight has been shown to influence the number of fibers in the pyramids within species, and could participate in high-interindividual variability of the CST (van Crevel and Verhaart, 1963; Towe and Luschei, 2013).

\section{Age}

Several studies about the effect of aging in different nervous tissue have been published and are summarized in Table 5 .

In the human SC, fiber counts and mean axonal diameter (Ohnishi et al., 1976; Zhou et al., 1997) as well as fiber density (Terao et al., 1994; Nakanishi et al., 2004) are believed to decrease with age. Whether this decrease in density is preferential to small vs. large fibers is debated (Terao et al., 1994; Nakanishi et al., 2004). With respect to human nerves, results are diverse and often contradictory. For the human superior laryngeal nerve, axonal counts have been reported as decreasing with age (Jacobs and Love, 1985; Mortelliti et al., 1990) or remaining constant (Tiago et al., 2007). The same trends were observed in animals, with decrease of fiber density with age. However, large discrepancies were found, for examples in monkeys (Morrison et al., 1990; Fortune et al., 2014), and rats (Jeronimo et al., 2005; Watanabe et al., 2007; Soltanpour et al., 2012). The tissue (e.g., PNS vs. CNS) and the species of origin may influence the evolution of morphometric parameters in regard to aging.
The effect of aging in the myelin sheath is poorly studied. One comment by Jacobs et al. suggested that thin or medium sized axons showed a disproportionately thick myelin sheath in older humans ( $>60$ years old), consisting in loss of the expected relationship between axonal diameter and myelin sheath thickness (Jacobs and Love, 1985).

\section{Gender}

Table 6 describes the effect of gender on axon morphology. Of particular interest, the study of Yang et al. (2008) showed that in young mice, males presented a higher total volume of myelinated fibers and myelin sheath than females did. A significant decrease in those parameters in male with aging was reported, whereas they increased with age in females. No sex difference for mean myelinated fiber diameter was found. They hypothesized that the increase in mean fiber diameter in males could be caused by the loss of the smaller fibers. In females, the increase in myelin sheath thickness could be explained by split of myelin lamellae, because of a shorter life span of oligodendrocytes. In a similar fashion, a group showed the importance of age on the SC but later (Zhou et al., 2000) refined their findings by specifying that the age-related reduction in axon diameter was seen in males only (Zhou et al., 1997, 2000). In the mice SC (cervical level), Cerghet et al. (2006) showed smaller levels of oligodendrocytes in females than in males as well as reduced myelin basic protein, hinting at a lesser degree of myelination in females (Cerghet et al., 2006). Interestingly, other studies did not find a significant effect of gender on axon morphometry (van Crevel and Verhaart, 1963).

Sexual dimorphism has already been established in the brain (particularly in the hippocampus) so even if to this day this issue has not been much addressed in the SC, it is likely that sexual

TABLE 5 | Evolution of morphometric data obtained from nervous tissue according to age in different species.

\begin{tabular}{|c|c|c|c|c|c|c|}
\hline Species/tissue & Number of fibers & Density & Mean axonal diameter & Myelin sheath & $g$-ratio & References \\
\hline Human spinal cord L1 & $\Downarrow$ & & $\Downarrow$ & & & Zhou et al., 1997 \\
\hline Human fasciculus gracilis C3 & $\Downarrow$ & & & & & Ohnishi et al., 1976 \\
\hline Human corticospinal tract & & $\Downarrow$ (small fibers) & & & & Terao et al., 1994 \\
\hline Human corticospinal tract & & $\Downarrow$ & & & & Nakanishi et al., 2004 \\
\hline Human sural nerve & $\Downarrow$ but $\Uparrow$ for small axons & $\Downarrow$ & & Constant until $\cong 60$ & & Jacobs and Love, 1985 \\
\hline Human optic nerve & Constant & & $\begin{array}{l}\text { Preferential large fiber } \\
\text { loss }\end{array}$ & & & $\begin{array}{l}\text { Repka and Quigley, } \\
1989\end{array}$ \\
\hline Human superior laryngeal nerve & Constant (myelinated fibers) & & No significant difference & & & Tiago et al., 2007 \\
\hline Human superior laryngeal nerve & $\Downarrow$ (myelinated fibers) & Constant & $\begin{array}{l}\Downarrow \text { of } 1-2 \mu \mathrm{m} \text { fibers and } \\
0-0.5 \mu \mathrm{m} \text { axons }\end{array}$ & & & Mortelliti et al., 1990 \\
\hline Human recurrent laryngeal nerve & $\Downarrow$ (myelinated fibers) & & $\Downarrow$ of $1-3 \mu \mathrm{m}$ axons & & & Tiago et al., 2007 \\
\hline Monkey optic nerve & & $\Downarrow$ & Constant & & & Morrison et al., 1990 \\
\hline Monkey optic nerve & Constant & & $\Uparrow$ & & & Fortune et al., 2014 \\
\hline Mice olfactory nerve & & Constant & $\Downarrow$ & & & Watanabe et al., 2007 \\
\hline Rat hypoglossal nerve (male) & Constant (myelinated) & & $\Downarrow$ & $\Downarrow$ & $\Downarrow$ & Soltanpour et al., 2012 \\
\hline Rat sural nerve & Constant for myelinated & $\Downarrow$ (myelinated) & $\begin{array}{l}\Uparrow \text { myelinated and axon } \\
\text { diameter }\end{array}$ & Myelin sheath area $\Uparrow$ & Constant & Jeronimo et al., 2005 \\
\hline Rat brain & & & $\Uparrow$ & $\begin{array}{l}\Uparrow \text { for } F \\
\Downarrow \text { for } M\end{array}$ & & Yang et al., 2008 \\
\hline
\end{tabular}

F, female; $M$, male. 
TABLE 6 | Evolution of morphometric data obtained from nervous tissue according to sex in different species.

\begin{tabular}{|c|c|c|c|c|c|c|}
\hline Species/tissue & Number of fibers & Density & Myelin sheath & $\begin{array}{l}\text { Mean axonal } \\
\text { diameter }\end{array}$ & g-ratio & References \\
\hline Human laryngeal nerve & & & & $M>F$ & $M>F$ & De Campos et al., 2014 \\
\hline Rat phrenic nerve & Myelinated: F > M & Myelinated: F > M & Similar & & Similar & Rodrigues et al., 2011 \\
\hline Rat brain & & & $\begin{array}{l}\text { Young: } M>F \\
\text { Old: } F>M\end{array}$ & Similar (myelinated) & & Yang et al., 2008 \\
\hline $\begin{array}{l}\text { Mice spinal cord cervical } \\
\text { ventral funiculus }\end{array}$ & & & $\begin{array}{l}\text { OLG: } M>F \\
\text { MBP levels: } M>F\end{array}$ & & & Cerghet et al., 2006 \\
\hline
\end{tabular}

F, female; M, male; OLG, oligodendrocytes.

dimorphism might be present in there too (Bear et al., 2007). For example, the sacral level in the SC differs from males to females since the former have supplementary motoneurons in the gray matter in order to control bulbocavernous muscles involved in ejaculation (Breedlove and Arnold, 1980; Forger and Breedlove, 1986; Wagner and Clemens, 1991; Bear et al., 2007). In addition, it seems that aging and sex would be interdependent factors for morphometry.

\section{Vertebral and Spinal Levels}

The number of fibers in the WM will necessarily vary according to the rostro-caudal location in the SC, with descending fibers reaching their targets and ascending fibers entering progressively (Standring, 2008). Ohnishi et al. (1976) have indeed reported a decrease in the number of myelinated fibers of the fasciculus gracilis in human between C3 and T5 (respectively 25,267 and 23,069 per $\mathrm{mm}^{2}$ ). In general, more studies covered cervical segments than thoracic and lumbar ones.

The variation of axon diameter regarding the vertebral level is not clear so far: Leenen et al. (1985) reported no difference in the rat pyramidal tract, whereas differences were reported in the human lateral CST (Terao et al., 1994) and in the human fasciculus gracilis (Ohnishi et al., 1976).

\section{Statistical Power}

Intra-species variability seems to be high, as noted by Verhaart (1947), van Crevel and Verhaart (1963), Jacobs and Love (1985), and Morrison et al. (1990). It is informative to look at the number of animals used in each article. For instance, Harding's results (Harding and Towe, 1985) are based on a total of two rats; Biendenbach's (Biedenbach et al., 1986) on three cats; Firmin et al. (2014) used two monkeys for the neuroanatomical part of his article. Leenen's study (Leenen et al., 1985) in rats was realized on five animals, similar to Ralston's study (Ralston et al., 1987) studying six monkeys. In addition to the relatively low number of animals per study, because most studies used TEM, in general only $1-6 \%$ of the area of the tract is considered in the analysis. Partial sampling can introduce variability and error in addition to not being representative (Fortune et al., 2014).

\section{Protocols}

Table 7 exemplifies some protocols used for characterizing axon morphology. The fairly large variability of protocols can partly explain the variability observed in the reported results across studies. Indeed, the choice of protocol can have several impacts on shrinkage, distortions and other artifacts. Another typical example that often occurs when imaging deep tissue, is that imperfect fixation of the myelin sheath with osmium (due to poor penetration) can induce lamellae separation (Harding and Towe, 1985).

Even with an optimal protocol, issues remain such as microscope resolution. The theoretical resolution with light microscopy is $\sim 300-350$ and $\sim 200-250 \mathrm{~nm}$ with numerical aperture of 1 (in air) and 1.5 (in oil), respectively (Bart, 2006; Madou, 2011; Nadeau, 2012; Bradshaw and Stahl, 2015), although in practice a resolution below $1 \mu \mathrm{m}$ is hard to obtain (Madou, 2011). As a result, approximately $20 \%$ of fibers are not detected when imaged with light microscopy (Arbuthnott et al., 1980; Biedenbach et al., 1986; Ralston et al., 1987; Firmin et al., 2014). To reduce the mismatch between neuroanatomical and electrophysiological measures of fibers diameter, Firmin et al. (2014) used electron microscopy to show that many more small axons (with a diameter of $0.5 \mu \mathrm{m}$ and less) were detected in comparison with previous studies that used light microscopy (Arbuthnott et al., 1980; Harding and Towe, 1985; Hildebrand et al., 1993; Firmin et al., 2014). The difficulty in detecting small fibers (less than $1 \mu \mathrm{m}$ ) comes with the challenge of accurately obtaining morphometry information such as diameter and myelin sheath thickness (Biedenbach et al., 1986; Firmin et al., 2014).

Lastly, most studies have employed a manual fiber identification and manual selection of the profile of interest. This procedure may induce a bias against small or ill-defined fibers (Biedenbach et al., 1986). Furthermore, the time needed to do this manual identification produces exhaustion-related bias and more importantly limits the area studied (More et al., 2011; Reynaud et al., 2012; Isaacs et al., 2014). For instance, Firmin et al. only sampled $0.015 \mathrm{~mm}^{2}$ of the tract in EM when the complete acquisition window was of $3.782 \mathrm{~mm}^{2}$ (Firmin et al., 2014).

There is a need for a thorough investigation of SC morphometry with high statistical power. To achieve this goal, analysis of the complete section of the SC (as opposed to samples) from several animals is necessary to provide a good overview of the inter-individual variability within species when all factors are accounted for (sex, weight, etc.). Due to the large area of the SC however $\left(\sim 1 \mathrm{~cm}^{2}\right.$ in human) and the small size of fibers $(\sim 1 \mu \mathrm{m})$, a fast imaging technique at high resolution is necessary. 
TABLE 7 | Histological protocols for ultrastructural observation of nervous tissue in literature.

\begin{tabular}{|c|c|c|c|c|c|}
\hline Species & Perfusion & Immersion & Osmification & Additional staining & References \\
\hline \multirow[t]{2}{*}{ Monkey } & $2 \%$ Glutaraldehyde - 2\% PFA & & & & Ralston et al., 1987 \\
\hline & $1 \%$ glutaraldehyde $-1 \%$ PFA & $\begin{array}{l}1 \% \text { glutaraldehyde - } 1 \% \\
\text { PFA }\end{array}$ & Osmium tetroxide $1 \%$ (1.5 h) & $\begin{array}{l}1 \% \text { toluidine blue }(\mathrm{OM}) \\
1 \% \text { uranyl acetate and } 1 \% \\
\text { lead acetate }(\mathrm{EM})\end{array}$ & Firmin et al., 2014 \\
\hline Cat & $\begin{array}{l}1.5 \% \text { glutaraldehyde }-1 \% \\
\text { PFA }-0.1 \% \text { picric acid }\end{array}$ & $\begin{array}{l}1.5 \% \text { glutaraldehyde }-1 \% \\
\text { PFA }-0.1 \% \text { picric acid }\end{array}$ & $\begin{array}{l}\text { Osmium tetroxide } 1-1.5 \% \\
\text { potassium ferricyanide }\end{array}$ & $\begin{array}{l}1 \% \text { uranyl acetate and } 0.1 \% \\
\text { lead citrate (EM) }\end{array}$ & Biedenbach et al., 1986 \\
\hline \multirow[t]{2}{*}{ Rat } & $\begin{array}{l}0.5 \% \text { PFA }-1.5 \% \\
\text { glutaraldehyde }-0.1 \% \text { picric } \\
\text { acid }\end{array}$ & $\begin{array}{l}0.5 \% \text { PFA }-1.5 \% \\
\text { glutaraldehyde }-0.1 \% \text { picric } \\
\text { acid }\end{array}$ & $\begin{array}{l}\text { Osmium tetroxide } 2-0.15 \% \\
\text { potassium ferrocyanide (EM) }\end{array}$ & $\begin{array}{l}5 \% \text { toluidine blue }(\mathrm{OM}) \\
\text { Uranyl acetate and lead } \\
\text { citrate }(\mathrm{EM})\end{array}$ & Leenen et al., 1985 \\
\hline & $\begin{array}{l}0.5 \% \text { glutaraldehyde }-4 \% \\
\text { PFA }\end{array}$ & $\begin{array}{l}0.5 \% \text { glutaraldehyde }-4 \% \\
\text { PFA (2nd animal) }\end{array}$ & $\begin{array}{l}\text { Osmium tetroxide } 2 \% \text { ( } 1 \text { st } \\
\text { animal) } \\
\text { Osmium tetroxide } 4-1.5 \% \\
\text { potassium ferrocyanide (2nd } \\
\text { animal) }\end{array}$ & $\begin{array}{l}\text { Methylene blue-azure II (1st } \\
\text { animal) } \\
\text { Methylene blue-azure II } \\
\text { (OM) or } 4 \% \text { uranyl acetate } \\
\text { and } 11.6 \% \text { lead acetate } \\
\text { (EM) (2nd animal) }\end{array}$ & Harding and Towe, 1985 \\
\hline Human & $\begin{array}{l}10 \% \text { formalin ( } 3.7-4.0 \% \\
\text { formaldehyde) through the } \\
\text { femoral artery }\end{array}$ & $\begin{array}{l}10 \% \text { formalin ( } 1 \text { week) } \\
5 \% \text { potassium dichromate } \\
\text { and } 5 \% \text { potassium } \\
\text { chromate ( } 2 \text { weeks) }\end{array}$ & & $\begin{array}{l}\text { luxol fast blue-periodic acid } \\
\text { Schiff-hematoxylin (LPH) }\end{array}$ & Souma et al., 2009 \\
\hline
\end{tabular}

To analyze these images, automatic and accurate segmentation softwares are needed.

\section{SUGGESTED PROTOCOL FOR PREPARING WHITE MATTER TISSUE}

As previously discussed, many factors can affect the quality of sample preparations such as the fixation method, fixative concentration, duration of fixation, temperature and $\mathrm{pH}$ of fixation, solution osmolarity, staining, buffer, dehydration, and embedding. Suggestions for optimal protocol are listed hereafter, which are based on existing literature and on the authors' research experience.

\section{Fixation Method}

The tissue can be fixed in two ways. The first method, called immersion fixation, consists of cutting the tissue into small pieces which are then submerged into fixatives until the tissue is set in place. The cutting of the sample into small pieces should be done with a razor blade by one quick slashing motion instead of several back-and-forth movements in order to avoid any tissue damage. The second method, called perfusion fixation, involves delivering the fixatives through the systemic circulatory system. Perfusion flowrate should be adjusted according to the blood pressure: a pressure too high could lead to vessels exploding, while a low pressure could have a detrimental effect on fixation speed.

It is generally accepted that vascular perfusion fixation is a necessary step for tissues that undergo rapid lysis after removal and for providing well-preserved axons and myelin (Palay et al., 1962; Williams and Jew, 1975; Langford and Coggeshall, 1980; Lamberts and Goldsmith, 1985; Chang and Slikker, 1995; Fix and Garman, 2000). Thus, if perfusion cannot be done (e.g., human tissue), the tissue needs to be immersed in the fixative solution as soon as possible after death in order to minimize tissue damage.

\section{Fixative Concentration}

A mixture of glutaraldehyde (Ga) and paraformaldehyde (PFA) is recommended for ultrastructural studies as it combines the high cross-linking ability of $\mathrm{Ga}$ and the fast action of the PFA (Williams and Jew, 1975; Lamberts and Goldsmith, 1985; Chang and Slikker, 1995; Fix and Garman, 2000; Brancroft, 2008; Hayat, 2012). The original paper by Karnovsky (1965) recommends a mixture of $5 \%$ glutaraldehyde and $4 \%$ formaldehyde, which is a higher concentration than what people typically use (Hayat, 2012). Other empirically-determined mixtures that are widely used for both structural and immunocytochemical studies consist of a modified Karnovsky solution by using it in half-strength formulation; $2 \%$ PFA and $2.5 \% \mathrm{Ga}$ in $0.1 \mathrm{M}$ Sodium Cacodylate (or phosphate buffer with a pH of 7.4) (Karnovsky, 1965; Dykstra and Reuss, 2003). The optimal concentration of Ga and PFA is difficult as the chemical interactions of these two fixatives with each other and with the tissue are still not completely understood (Glauert and Lewis, 2014). A relatively wide range of $\mathrm{Ga}$ concentrations (about 1.5-4\%) has been used in animal tissue fixation (Hayat, 2012). In general, a low concentration of fixative requires a longer duration of fixation, but long Ga fixation (over a week) can cause tissue shrinkage (Hayat, 2012). High concentrations $(>4 \%)$ are also unsuitable since they destroy the ultrastructure (Bozzola and Russel, 1992). The presence of Ga affects the process of protein cross-linking and the osmolarity. High Ga concentrations (30\% and more) can lead to severe shrinkage whereas low Ga concentration ( $0.5 \%$ and below) can cause severe cell components extraction if osmolarity is not controlled (Dykstra and Reuss, 2003; Hayat, 2012). Such extreme 
osmolarity of the fixative leads to myelin shrinkage, swelling or vacuolation.

Note that Ga should not be used with coherent anti-stokes Raman spectroscopy (CARS) imaging because it discards the anti-stokes effect (Bélanger et al., 2009). In this case, Ga can simply be discarded or replaced with acrolein.

\section{Duration of Fixation}

The penetration of fixatives into the tissues is described by Fick's second law (Yong-Hing et al., 2005; Thavarajah et al., 2012): $\frac{\partial c_{i}}{\partial t}=D \frac{\partial c_{i}}{\partial x}$ where $i$ is fixative considered, $c_{i}$ the fixative concentration, $x$ is the axis of penetration, $t$ the time of fixative penetration and $D$ the diffusion coefficient of the fixative. Assuming that the volume of a fixative is large enough and the nominal concentration $c_{0}$ of the solution is unchanged at the boundary of the tissue, the fixative concentration is:

$$
c_{i}(x, t)=c_{0}\left(1-\operatorname{erf}\left(\frac{x}{2 \sqrt{D t}}\right)\right) \approx c_{0}\left(1-\frac{x}{\sqrt{D t}}\right)
$$

Let's define $d$, the depth of penetration at which $50 \%$ of the nominal concentration $\left(c_{i}(d, t)=1 / 2 c_{0}\right)$ is obtained. We can write $\mathrm{d} \approx 1 / 2 \sqrt{\mathrm{Dt}}$.

The diffusion coefficient $\mathrm{D}$ is influenced by temperature (T), fluid viscosity $(\eta)$, the size of the chemical compounds (r) according to the Stokes-Einstein law for solutions with low Reynolds numbers: $D=\frac{k_{B} T}{6 \pi \eta r}$ where $k_{B}$ is Boltzmann's constant (Mehrer and Stolwijk, 2009). Thus, high temperatures, low fixative solution viscosity and small chemical compounds will increase the rate of diffusion.

The diffusion values for osmium tetroxide $\left(\mathrm{OsO}_{4}\right), \mathrm{Ga}$ and formaldehyde are respectively $D=0.2,0.34$ and $2.010^{-9}$ $\mathrm{m}^{2} / \mathrm{s}$ (Johannessen, 1977). Thus, using $d \approx 1 / 2 \sqrt{D t}$, at room temperature, Ga and PFA penetrate the tissue by 1 and $3 \mathrm{~mm}$ respectively after $4 \mathrm{~h}$, or by 3 and $7 \mathrm{~mm}$ after $24 \mathrm{~h}$.

Regarding Osmium penetration, the reaction with unsaturated lipids drastically reduces the permeability of the membranes and thus the diffusion within the tissue. Osmium staining is thus strongly reduced after $200 \mu \mathrm{m}$. Strategies have been developed to improve Osmium penetration, by reducing temperature during the osmification process (osmium reaction is more greatly reduced than diffusivity) or/and by using a reducing agent to improve contrast (Mikula et al., 2012; Hua et al., 2015)

\section{Temperature and $\mathbf{P H}$}

At low temperatures, the penetration rate is slowed down, as well as the reaction of the fixatives (which affect the permeability of the tissue membranes). At high temperatures autolytic changes occur more rapidly (Hunter et al., 1993) which cause the formation of fixation artifacts (e.g., cell shrinkage, cell volume and shape changes) (Hayat, 2012). Some investigators demonstrated that formaldehyde fixation at room temperature induces poor preservation (Cross et al., 1990). However, depending on the type of tissue, Ga can be used at temperatures ranging $0-25^{\circ} \mathrm{C}$ with little morphological differences in the ultrastructure (Hayat, 2012). Regarding perfusion, cold temperatures affect some metabolic processes and can induce loss of these structures (Hayat, 2012). In vascular perfusion, using a Ga solution below body temperature may cause vasoconstriction (Fix and Garman, 2000).

When cells die during the fixation process, the lysosomes release their contents and make the $\mathrm{pH}$ of the tissue acidic. The optimal $\mathrm{pH}$ is close to that of the tissue and has to be maintained during the entirety of the tissue preparation process. Indeed, a change in the tissue $\mathrm{pH}$ could severely alter its ultrastructure. Since the average $\mathrm{pH}$ of most animal cells is 7.4 it is recommended to adjust the $\mathrm{pH}$ of the fixative solution to the physiological range of 7.2-7.5, especially when using $\mathrm{Ga}$ or osmium tetroxide $\left(\mathrm{OsO}_{4}\right)$ (Peters, 1970).

\section{Osmolarity}

The osmolarity of a fixative solution has a direct effect on the myelin morphology. Axon size and shape may be affected by the buffer or the fixative solution's osmolarity. Osmolarity depends on the type of buffer and the concentration of the fixatives (Schultz and Karlsson, 2006). At low osmolarity ( $\leq 320$ $\mathrm{mOsmol}$ ), the fixation is very poor and causes cell swelling. The osmolarity of the fixative solution should be slightly hypertonic (400-600 mOsmol) to prevent blood vessels from bursting during perfusion (Fix and Garman, 2000; Schultz and Karlsson, 2006). Higher osmolarity (>1,000 mOsmol) could induce considerable tissue shrinkage and widening of the extracellular space (Ohnishi et al., 1976). As the resistance in blood vessels increases during perfusion, the fixative flow stops rapidly through the specimen, resulting in a very poor fixation (Ohnishi et al., 1976; Schultz and Karlsson, 2006). Electrolytes, especially $\mathrm{CaCl}_{2}$, when added to isotonic fixative solutions can overcome the issues of osmolarity and decrease fixation artifacts such as swelling and shrinkage (Hayat, 2012). To increase the osmolarity, saccharose or tannic acid can be added to the fixative (Hayat, 2012).

\section{Osmification}

Osmium tetroxide $\left(\mathrm{OsO}_{4}\right)$ has two interesting effects: it fixes the lipids and it stain the membranes for optical or electron microscopy. Without osmium, lipids are dissolved in the dehydration process (Robertson, 1957; Langford and Coggeshall, 1980; Dykstra and Reuss, 2003; Bruce-Gregorios, 2006; Fujimoto et al., 2012; Glauert and Lewis, 2014). In electron microscopy osmium improves the back-scattered electron density thanks to its large atomic number $(Z=76)$ and the conductivity of the sample's surface (Bozzola and Russel, 1992). As discussed earlier, osmium has a short penetration depth, and it is thus recommended to use a small sample size in one dimension or to image a slice close to the surface $(<200 \mu \mathrm{m})$. Note that other electron-dense stains exist, such as uranium salts, potassium permanganate and ruthenium tetroxide (Hayat, 2012).

\section{Dehydration}

After being post-fixed in osmium tetroxide, the specimen needs to be dehydrated at room temperature. The purpose of dehydration is to remove water from the tissue so that the embedding media can infiltrate the tissue. Ethanol (mixed with propylene oxide) or acetone solvent are commonly used. Some electron microscopy textbooks suggest that ethanol with 
propylene oxide present better infiltration than acetone and would be recommended for large samples (Bozzola and Russel, 1992; Glauert and Lewis, 2014). However, propylene oxide is more toxic than ethanol and acetone appears to cause less shrinkage than ethanol (Dykstra and Reuss, 2003; Rana, 2008).

\section{Embedding}

As acrylic resin is harder than paraffin, the use of this embedding media allows for cutting thinner sections than with paraffin $(0.1-$ 2 vs. 3-6 $\mu \mathrm{m})$, in turn allowing greater resolution for optical microscopy (Sheehan and Hrapchak, 1980; Bancroft and Gamble, 2002; Lowe and Anderson, 2014).

In order to cut the hard acrylic resin, diamond or tungstencarbide knifes can be used. Diamond knives are used to cut ultrathin sections for TEM $(<100 \mathrm{~nm})$, but they are usually only a couple of millimeters long and can only cut samples of that size range. Tungsten-carbide blades can cut larger samples however produces thicker slices $(\sim 1 \mu \mathrm{m})$.

The choice of epoxy resin is determined by its hardness, its viscosity (and thus its penetration), its cutting behavior (very homogeneous resins are easier to cut), and its resistance under the electron beam. "Embed 812 " is a standard epoxy resin that satisfies the above-mentioned criteria.

\section{NOVEL TECHNIQUES AND PERSPECTIVES}

Methods for preparing tissues and analyzing their ultrastructure have not fundamentally changed since they were first developed in the 1960s. However, recent techniques have been introduced that can improve the current state-of-the-art of mapping axon morphometric in the SC (Mikula and Denk, 2015). This section lists some of the new technologies that feature largescale microscopy, endogenous contrast to myelin, and analysis software for axon and myelin segmentation.

\section{Coherent Anti-stokes Raman Scattering (CARS)}

Currently, the observation of axons and myelin sheath relies on the conventional stains mentioned above. However, the preservation of myelin ultrastructure is strongly sensitive to fixation artifacts. Therefore, new myelin imaging techniques have been developed during the last decades that can be used without fixing the tissue or using immunostaining with myelin basic proteins (MBP) and other agents that can identify the ultrastructure in situ (fluorescence) (Wang et al., 2010; Bajaj et al., 2013).

Coherent Anti-Stokes Raman Scattering (CARS) is a recent imaging technique that has proven useful for imaging myelin (Wang et al., 2005; Bélanger et al., 2009). This modality is sensitive to the biochemical nature of tissues. When the frequency difference between two laser beams targeting a sample is resonant with the Raman vibrations of lipid $(\mathrm{CH} 2$ at 2,850 $\mathrm{cm}^{-1}$ ), the lipids that make the myelin membrane emit light. Axial and lateral CARS resolution are respectively about 0.70 and $0.28 \mu \mathrm{m}$ (Wang et al., 2005). As CARS relies on the endogenous chemical contrast provided by lipids in the myelin sheath it abolishes the need for staining and dehydration/embedding (the critical step for myelin damage), therefore allowing for more realistic measures of g-ratio and myelin sheath thickness (Wang et al., 2005; Bélanger et al., 2009; De Vito et al., 2015). Additionally, this technique can image myelin in vivo, allowing researchers to follow demyelination in animal models of MS or nerve crush injury (Henry et al., 2009; Bélanger et al., 2011; Imitola et al., 2011). An example of a CARS image is shown in Figure 3.

\section{Optical Coherence Microscopy (OCM)}

Optical Coherence microscopy uses the backscattered light due to refractive index variations in the tissue as a source of endogenous contrast. Myelin produces a high intrinsic backscattering signal due to the high refractive index of the lipid-rich myelin sheath. Just like CARS, OCM performs virtual sectioning by selecting a slice (through interferometry) at a depth of up to one hundred microns. Preventing the sectioning step prevents tissue damage and allows in vivo imaging (Ben Arous et al., 2011). Axial and lateral resolution can reach respectively 1.15 and $0.5 \mu \mathrm{m}$ (Ben Arous et al., 2011). OCM provides not only quantitative measurements of myelin optical properties but also novel optical markers of cell viability and myelination (Srinivasan et al., 2012). The limited resolution, however, prevents fine measurement of axon morphometry.

\section{Third Harmonic Generation Microscopy (THG)}

Third harmonic generation (THG) microscopy is a coherent, nonlinear, dye-free imaging modality. THG can reach a micrometer resolution and has been used to monitor myelin loss and recovery in the mouse CNS (Farrar et al., 2011). Just like the two previous techniques, THG does not require any exogenous dye or fluorescent proteins and provides 3D structural images. It can be combined with other non-linear optic such as the two-photon excitation fluorescence (2PEF) and second harmonic generation (SHG). The resolution can be improved down to $5 \mathrm{~nm}$ if a super-resolution technique is used (Sandkuijl et al., 2013; Dashtabi et al., 2017).

\section{Immunostaining in Combination with Confocal Microscopy}

Immunostaining is an antibody-based method to detect a specific protein in the tissue. Immunostaining based on myelin basic proteins (MBP) in combination with confocal microscopy provides a sensitive and reliable method to observe the fine structure of myelin sheath (Xing et al., 2012).

Confocal microscopy has a pixel resolution around $0.3 \mu \mathrm{m}$ (Conn, 2010). Using laser-scanning confocal microscope, axial and lateral resolution can reach 38 and $122 \mathrm{~nm}$ respectively (Potrusil et al., 2012), and can image a slice a couple of hundred microns deep in the tissue, allowing in vivo imaging. For electron microscopy, antibodies are labeled with gold particles that can be observed with TEM. However, immune-EM can be technically challenging, expensive and requires rigorous tissue fixation (Xing et al., 2012). Note that confocal microscopy does not necessarily require fluorescence labeling. Using multiple confocal lasers 


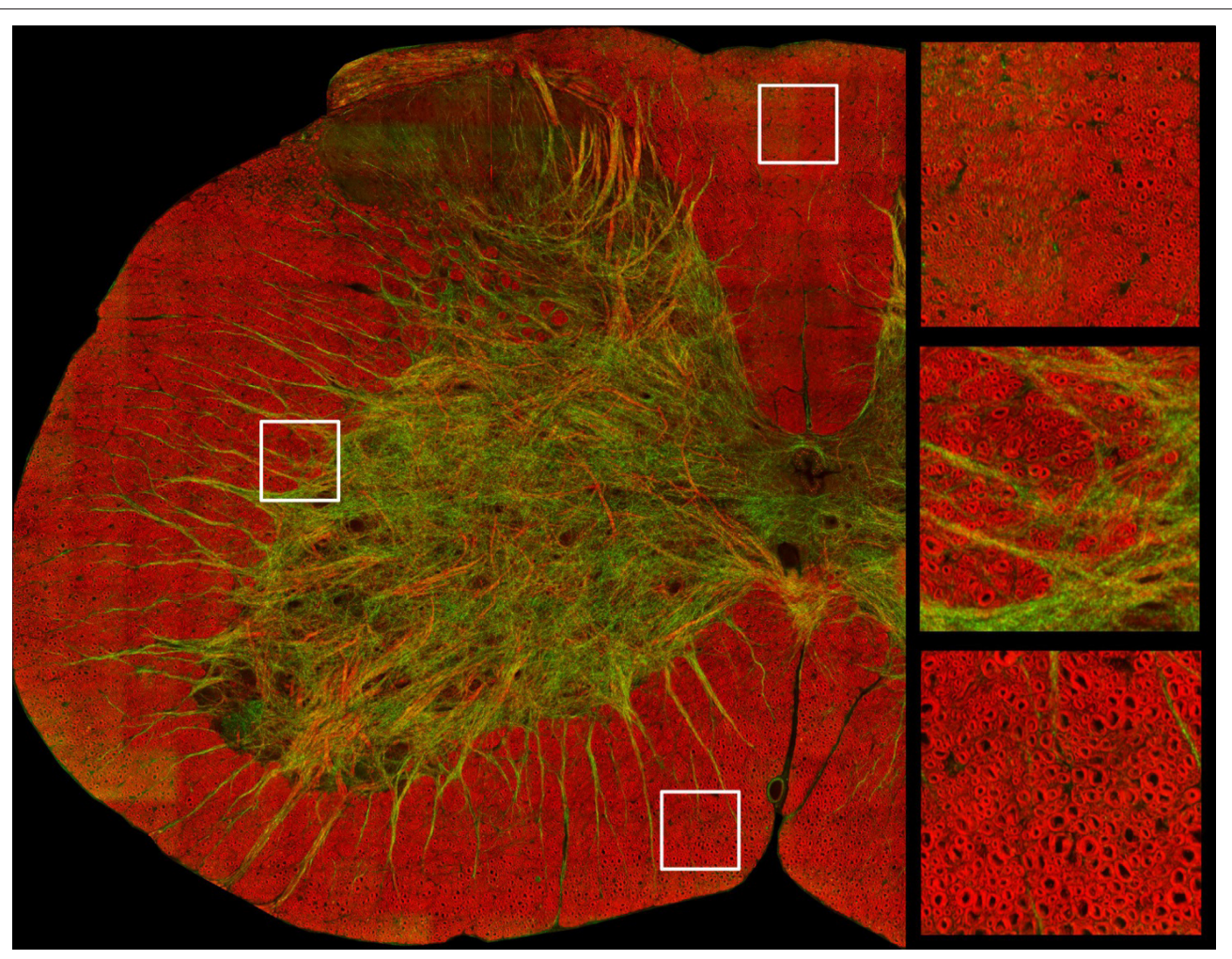

FIGURE 3 | Image of a cross-section of a mouse spinal cord based on coherent anti-stokes Raman spectroscopy, which is tuned to exhibit signal from myelin sheath. Axial axons appear in red, while lateral fibers and some vessels appear in green. Zoomed panels focus on the dorsal (top right) and ventral white matter (bottom right) and in the ascending reticulospinal/fasciculus proprius region (middle right). Courtesy of Erik Bélanger, Sophie Laffray and Daniel Côté.

tuned at different wavelengths, Spectral Confocal Reflectance microscopy (SCoRe) can be specific to myelin, making the application of this technique easier on animals other than rodents (Schain et al., 2014).

\section{Slide Scanner and Stitching Algorithms}

Imaging large sections of a sample, such as a complete SC transection, has become possible through the use of a motorized stage combined with an algorithm that stitches together small field-of-view images acquired at high resolution. These largescale images can then be observed and analyzed on a virtual slide viewer (Weinstein et al., 2009; Pantanowitz et al., 2011).

Alternatively, whole-slide scanners provide a high-speed standardized acquisition with predefined parameters, with the ability to image up to 200 slides in one night, in bright field or with fluorescence, at 20 or $40 \times$ (Weinstein et al., 2009; Nederlof et al., 2011; Pantanowitz et al., 2011; Ameisen et al., 2012; Laurent et al., 2013; Gallas et al., 2014). A recent example of the use of whole-slide scanners is the BigBrain: a whole human brain scanned at $20 \mu \mathrm{m}$ resolution (Amunts et al., 2013).

\section{Automatic Segmentation}

Automated analysis has become important for large-scale morphometric studies, as manual identification of axons is long, tedious and subject to user bias (More et al., 2011). Several algorithms exist for axon and myelin segmentation (Romero et al., 2000; More et al., 2011; Bégin et al., 2014; Mesbah et al., 2016; Zaimi et al., 2016, 2017). Following segmentation of axon and myelin, metrics such as distribution of axon diameter, mean myelin thickness or myelin volume fraction can be more readily computed (Bégin et al., 2014).

The use of axon segmentation software has shown encouraging results in terms of sensitivity and accuracy, especially when compared to manual identification (Reynaud et al., 2012; Isaacs et al., 2014). For example, Bégin et al. (2014) segmented $60 \%$ of the complete section of a mouse SC in $4 \mathrm{~h}$, counting a total of 32,000 axons. More et al. (2011) have identified $84.3 \%$ of axons in a whole SEM slice of peripheral nerve ( 4 ms/axon) and were able to measure myelin sheath thickness and axon diameter. Figure 4 illustrates a semi-automatic segmentation on SC tissue.

A fully automatic approach with perfect accuracy is, however, difficult to achieve. For example, algorithms can sometimes fail to discriminate fibers that are too packed, or to distinguish between neuronal fibers and other tissue components such as blood vessels. Hence, manual intervention is often required (More et al., 2011; Bégin et al., 2014; Isaacs et al., 2014; Zaimi et al., 2016). Machine learning methods (e.g., deep learning algorithm), could potentially be trained to overcome these issues and avoid human intervention (Cireşan et al., 2013; Zaimi et al., 2017).

In addition to the segmentation issues, the metrics extracted are potentially affected by the quality of the image. The 

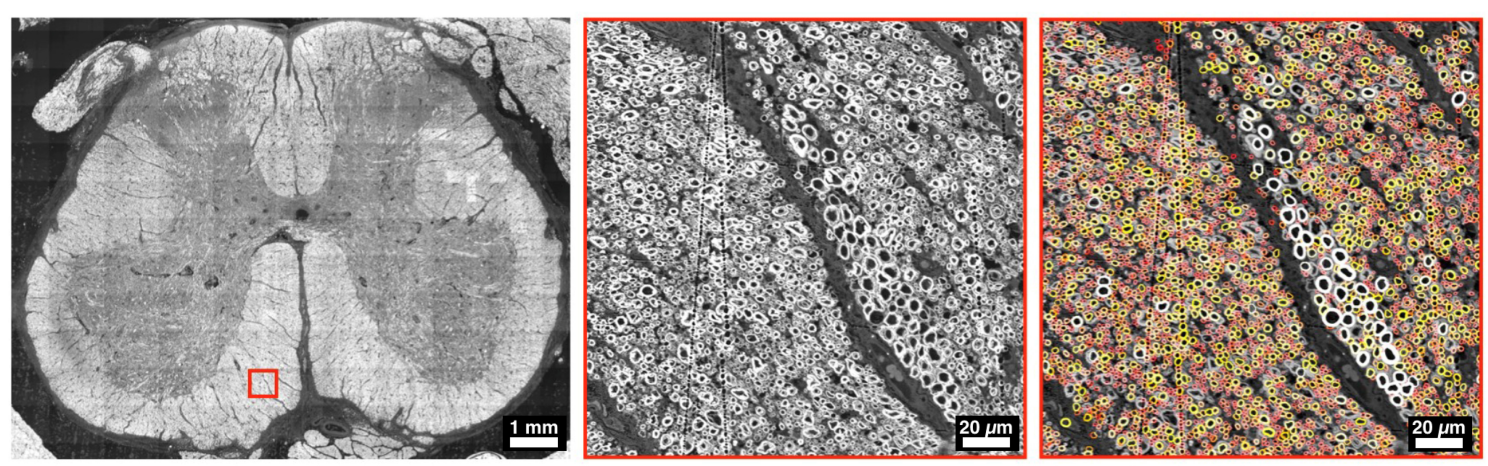

FIGURE 4 | Example of a whole slice of a human SC at L5 level, imaged with electron microscopy. The middle panel focuses in the ventral region, and the right panel shows an overlay of myelin segmentation, color-coded for axon diameter (red: small, white/yellow: big). Segmentation was performed using AxonSeg (https://github. com/neuropoly/axonseg).

inherent point spread function of the imaging system, a bad focus, or an inhomogeneous contrast/illumination (e.g., due to inhomogeneous staining) can lead to over- or under-estimated morphological values (e.g., myelin thickness, myelin volume). An additional challenge is thus to use an imaging system that is highly stable on the entire slice.

\section{CONCLUDING REMARKS}

In view of the existing literature, complete cartography of the SC WM microstructure is still difficult to achieve. The conventional procedures for histology of the central nervous system are invasive (cutting, staining) and face a constant trade-off between resolution and field-of-view. Quantitative descriptions of WM axons are mostly concerned the corticospinal or the pyramidal tracts. Results, however, are highly variable across studies, which could be attributed to differences in protocols, terminology, precise location of the region of interest and user bias. With the recent development of high-resolution, dye-free, in depth, whole slide imaging systems, combined with stitching and fully-automated segmentation algorithms, reproducible and comprehensive measures of axon morphometry in the spinal cord can be obtained. These new techniques can help pave the way toward large-scale imaging and characterization of WM microstructure across species.

\section{REFERENCES}

Altman, J., and Bayer, S. A. (2001). Development of the Human Spinal Cord: An Interpretation Based on Experimental Studies in Animals. New York, NY: Oxford University Press.

Ameisen, D., Le Naour, G., and Daniel, C. (2012). Technologie des lames virtuelles. Med. Sci. 28, 977-982. doi: 10.1051/medsci/20122811017

Amunts, K., Lepage, C., Borgeat, L., Mohlberg, H., Dickscheid, T., Rousseau, M. E., et al. (2013). BigBrain: an ultrahigh-resolution 3d human brain model. Science 340:1472. doi: 10.1126/science.1235381

Arbuthnott, E. R., Ballard, K. J., Boyd, I. A., and Kalu, K. U. (1980). Quantitative study of the non-circularity of myelinated peripheral nerve fibres in the cat. $J$. Physiol. 308, 99-123. doi: 10.1113/jphysiol.1980.sp013464

\section{AUTHOR CONTRIBUTIONS}

BP conducted the literature review on axon and myelin and wrote the article. AS conducted the review on the suggested protocol and wrote the article. TD conducted the review on the novel perspectives and wrote the article. NS, SR, and JC-A wrote and reviewed the article.

\section{FUNDING}

Study funded by the Canada Research Chair in Quantitative Magnetic Resonance Imaging (JC-A), the Canadian Institute of Health Research [CIHR FDN-143263], the Canada Foundation for Innovation [32454], the Fonds de Recherche du Québec Santé [28826], the Fonds de Recherche du Québec - Nature et Technologies [2015-PR-182754], the Natural Sciences and Engineering Research Council of Canada [435897-2013], the IVADO grant program and the Quebec BioImaging Network.

\section{ACKNOWLEDGMENTS}

The authors thank Dr. Daniel Côté and Dr. Erik Bélanger for providing their CARS images, Dr. Nadine Blumer for proofreading the manuscript and members of the NeuroPoly Lab for fruitful discussions.

Assaf, Y., Blumenfeld-Katzir, T., Yovel, Y., and Basser, P. J. (2008). Axcaliber: a method for measuring axon diameter distribution from diffusion MRI. Magn. Reson. Med. 59, 1347-1354. doi: 10.1002/mrm. 21577

Bajaj, A., Laplante, N. E., Cotero, V. E., Fish, K. M., Bjerke, R. M., Siclovan, T., et al. (2013). Identification of the protein target of myelin-binding ligands by immunohistochemistry and biochemical analyses. J. Histochem. Cytochem. 61, 19-30. doi: 10.1369/0022155412467353

Bancroft, J. D., and Gamble, M. (2002). Theory and Practice of Histological Techniques. London: Churchill Livingstone.

Barazany, D., Basser, P. J., and Assaf, Y. (2009). In vivo measurement of axon diameter distribution in the corpus callosum of rat brain. Brain 132, 1210-1220. doi: 10.1093/brain/awp042 
Bart, J. C. J. (2006). Plastics Additives: Advanced Industrial Analysis. Amsterdam: IOS Press.

Bear, M. F., Connors, B. W., and Paradiso, M. A. (2007). Neuroscience. Philadelphia, PA: Lippincott Williams and Wilkins.

Bégin, S., Dupont-Therrien, O., Bélanger, E., Daradich, A., Laffray, S., De Koninck, Y., et al. (2014). Automated method for the segmentation and morphometry of nerve fibers in large-scale CARS images of spinal cord tissue. Biomed. Opt. Express 5, 4145-4161. doi: 10.1364/BOE.5.004145

Bélanger, E., Bégin, S., Laffray, S., De Koninck, Y., Vallée, R., and Côté, D. (2009). Quantitative myelin imaging with coherent anti-Stokes Raman scattering microscopy: alleviating the excitation polarization dependence with circularly polarized laser beams. Opt. Express 17, 18419-18432. doi: 10.1364/OE.17.018419

Bélanger, E., Henry, F. P., Vallée, R., Randolph, M. A., Kochevar, I. E., Winograd, J. M., et al. (2011). In vivo evaluation of demyelination and remyelination in a nerve crush injury model. Biomed. Opt. Express 2, 2698-2708. doi: 10.1364/BOE.2.002698

Ben Arous, J., Binding, J., Léger, J.-F., Casado, M., Topilko, P., Gigan, S., et al. (2011). Single myelin fiber imaging in living rodents without labeling by deep optical coherence microscopy. J. Biomed. Opt. 16, 116012-1160129. doi: $10.1117 / 1.3650770$

Biedenbach, M. A., De Vito, J. L., and Brown, A. C. (1986). Pyramidal tract of the cat: axon size and morphology. Exp. Brain Res. 61, 303-310. doi: 10.1007/BF002 39520

Bozzola, J. J., and Russel, D. L. (1992). Electron Microscopy: Principles and Techniques for Biologists. Sudbury, ON: Jones and Bartlett Publishers.

Bradshaw, R. A., and Stahl, P. D. (2015). Encyclopedia of Cell Biology. San Diego, CA: Elsevier Science.

Brancroft, J. D. (2008). Theory and Practive of Histological Techniques. Philadelphia, PA: Elsevier Heatl Science.

Breedlove, S. M., and Arnold, A. P. (1980). Hormone accumulation in a sexually dimorphic motor nucleus of the rat spinal cord. Science 210, 564-566. doi: $10.1126 /$ science.7423210

Brodal, P. (2004). The Central Nervous System: Structure and Function. New York, NY: Oxford University Press.

Brodal, P. (2010). The Central Nervous System. New York, NY: Oxford University Press.

Brösamle, C., and Schwab, M. (2000). Ipsilateral, ventral corticospinal tract of the adult rat: ultrastructure, myelination and synaptic connections. J. Neurocytol. 29, 449-507. doi: 10.1023/A:1007297712821

Brown, L. T. Jr. (1971). Projections and termination of the corticospinal tract in rodents. Exp. Brain Res. 13, 432-450.

Bruce-Gregorios, J. (2006). Histopathologic Techniques. Quezon City: Goodwill Trading Co., Inc.

Cerghet, M., Skoff, R. P., Bessert, D., Zhang, Z., Mullins, C., and Ghandour, M. S. (2006). Proliferation and death of oligodendrocytes and myelin proteins are differentially regulated in male and female rodents. J. Neurosci. 26, 1439-1447. doi: 10.1523/JNEUROSCI.2219-05.2006

Chang, L. W., and Slikker, W. (1995). Neurotoxicology: Approaches and Methods. San Diego: Elsevier Science.

Chen, J. T., Easley, K., Schneider, C., Nakamura, K., Kidd, G. J., Chang, A., et al. (2013). Clinically feasible MTR is sensitive to cortical demyelination in MS. Neurology 80, 246-252. doi: 10.1212/WNL.0b013e31827 deb99

Chung, K., and Coggeshall, R. E. (1983). Numbers of axons in lateral and ventral funiculi of rat sacral spinal cord. J. Comp. Neurol. 214, 72-78. doi: 10.1002/cne.902140107

Chung, K., Langford, L. A., Applebaum, A. E., and Coggeshall, R. E. (1979). Primary afferent fibers in the tract of Lissauer in the rat. J. Comp. Neurol. 184, 587-598. doi: 10.1002/cne.901840310

Chung, K., Sharma, J., and Coggeshall, R. E. (1985). Numbers of myelinated and unmyelinated axons in the dorsal, lateral, and ventral funiculi of the white matter if the S2 segment of cat spinal cord. J. Comp. Neurol. 234, 117-121. doi: 10.1002/cne.902340109

Cireşan, D. C., Giusti, A., Gambardella, L. M., and Schmidhuber, J. (2013). "Mitosis detection in breast cancer histology images with deep neural networks," in Medical Image Computing and Computer-Assisted Intervention - MICCAI 2013: 16th International Conference, Nagoya, Japan, September 22-26, 2013,
Proceedings, Part II, eds K. Mori, I. Sakuma, Y. Sato, C. Barillot, and N. Navab (Berlin; Heidelberg: Springer), 411-418.

Conn, M. (2010). Techniques in Confocal Microscopy. Oxford: Elsevier.

Cross, S. S., Start, R. D., and Smith, J. H. (1990). Does delay in fixation affect the number of mitotic figures in processed tissue? J. Clin. Pathol. 43, 597-599. doi: $10.1136 /$ jcp.43.7.597

Dashtabi, M. M., Arabanian, A. S., and Massudi, R. (2017). Axial resolution enhancement of third harmonic generation microscopy by harmonic focal point axial modulation. Appl. Phys. Lett. 110:071106. doi: 10.1063/1.4976520

De Campos, D., Heck, L., Jotz, G. P., and Xavier, L. L. (2014). Degree of myelination (g-ratio) of the human recurrent laryngeal nerve. Eur. Arch. Oto-Rhino-Laryngol. 271, 1277-1281. doi: 10.1007/s00405-013-2690-y

Demyer, W. (1959). Number of axons and myelin sheaths in adult human medullary pyramids study with silver impregnation and iron hematoxylin staining methods. Neurology 9, 42-42. doi: 10.1212/WNL.9.1.42

de Oliveira-Souza, R. (2012). The human extrapyramidal system. Med. Hypotheses 79, 843-852. doi: 10.1016/j.mehy.2012.09.004

De Vito, G., Canta, A., Marmiroli, P., and Piazza, V. (2015). A largefield polarisation-resolved laser scanning microscope: applications to CARS imaging. J. Microsc. 260, 194-199. doi: 10.1111/jmi.12282

Dunkerley, G. B., and Duncan, D. (1969). A light and electron microscopic study of the normal and the degenerating corticospinal tract in the rat. J. Comp. Neurol. 137, 155-183. doi: 10.1002/cne.901370204

Duval, T., McNab, J. A., Setsompop, K., Witzel, T., Schneider, T., Huang, S. Y., et al. (2015). In vivo mapping of human spinal cord microstructure at $300 \mathrm{mT} / \mathrm{m}$. Neuroimage 118, 494-507. doi: 10.1016/j.neuroimage.2015.06.038

Dykstra, M. J., and Reuss, L. E. (2003). Biological Electron Microscopy: Theory, Techniques, and Troubleshooting. New York, NY: Springer.

Farrar, M. J., Wise, F. W., Fetcho, J. R., and Schaffer, C. B. (2011) In vivo imaging of myelin in the vertebrate central nervous system using third harmonic generation microscopy. Biophys. J. 100, 1362-1371. doi: 10.1016/j.bpj.2011.01.031

Firmin, L., Field, P., Maier, M. A., Kraskov, A., Kirkwood, P. A., Nakajima, K., et al. (2014). Axon diameters and conduction velocities in the macaque pyramidal tract. J. Neurophysiol. 112, 1229-1240. doi: 10.1152/jn.00720.2013

Fix, A. S., and Garman, R. H. (2000). Practical aspects of neuropathology: a technical guide for working with the nervous system. Toxicol. Pathol. 28, 122-131. doi: 10.1177/019262330002800115

Fjær, S., Bø, L., Lundervold, A., Myhr, K.-M., Pavlin, T., Torkildsen, O., et al. (2013). Deep gray matter demyelination detected by magnetization transfer ratio in the cuprizone model. PLoS ONE 8:e84162. doi: 10.1371/journal.pone.0084162

Forger, N. G., and Breedlove, S. M. (1986). Sexual dimorphism in human and canine spinal cord: role of early androgen. Proc. Natl. Acad. Sci. U.S.A. 83, 7527-7531. doi: 10.1073/pnas.83.19.7527

Fortune, B., Reynaud, J., Cull, G., Burgoyne, C. F., and Wang, L. (2014). The effect of age on optic nerve axon counts, SDOCT scan quality, and peripapillary retinal nerve fiber layer thickness measurements in Monkeys. Transl. Vis. Sci. Technol. 3:2. doi: 10.1167/tvst.3.3.2

Fujimoto, T., Ohsaki, Y., Suzuki, M., and Cheng, J. (2012). Imaging lipid droplets by electron microscopy. Methods Cell Biol. 116, 227-251. doi: 10.1016/B978-0-12-408051-5.00012-7

Gallas, B. D., Gavrielides, M. A., Conway, C. M., Ivansky, A., Keay, T. C., Cheng, W.-C., et al. (2014). Evaluation environment for digital and analog pathology: a platform for validation studies. J. Med. Imag. 1:37501. doi: 10.1117/1.JMI.1.3.037501

Glauert, A. M., and Lewis, P. R. (2014). Biological Specimen Preparation for Transmission Electron Microscopy. Princeton, NJ: Princeton University Press.

Graf von Keyserlingk, D., and Schramm, U. (1983). Diameter of axons and thickness of myelin sheaths of the pyramidal tract fibres in the adult human medullary pyramid. Anat. Anz. 157, 97-111.

Gramsbergen, A. (2005). Postural control in man: the phylogenetic perspective. Neural Plast. 12, 77-88. doi: 10.1155/NP.2005.77

Hanaway, J., Woolsey, T. A., Gado, M. H., and Roberts, M. P. (1998). The Brain Atlas: A Visual Guide to the Human Central Nervous System. Indianapolis: Wiley.

Harding, G. W., and Towe, A. L. (1985). Fiber analysis of the pyramidal tract of the laboratory rat. Exp. Neurol. 87, 503-518. doi: 10.1016/0014-4886(85)90180-3 
Hayat, M. A. (2012). Fixation for Electron Microscopy. New York, NY: Elsevier.

Heffner, R., and Masterton, B. (1975). Variation in form of the pyramidal tract and its relationship to digital dexterity. Brain Behav. Evol. 12, 161-200. doi: $10.1159 / 000124401$

Heffner, R. S., and Masterton, R. B. (1983). The role of the corticospinal tract in the evolution of human digital dexterity. Brain Behav. Evol. 23, 165-183. doi: $10.1159 / 000121494$

Henry, F. P., Côté, D., Randolph, M. A., Rust, E. A., Redmond, R. W., Kochevar, I. E., et al. (2009). Real-time in vivo assessment of the nerve microenvironment with coherent anti-stokes Raman scattering microscopy. Plast. Reconstr. Surg. 123, 123S-130S. doi: 10.1097/PRS.0b013e318191c5b8

Hildebrand, C., and Hahn, R. (1978). Relation between myelin sheath thickness and axon size in spinal cord white matter of some vertebrate species. J. Neurol. Sci. 38, 421-434. doi: 10.1016/0022-510X(78)90147-8

Hildebrand, C., Remahl, S., Persson, H., and Bjartmar, C. (1993). Myelinated nerve fibres in the CNS. Prog. Neurobiol. 40, 319-384. doi: 10.1016/0301-0082(93)90015-K

Hua, Y., Laserstein, P., and Helmstaedter, M. (2015). Large-volume en-bloc staining for electron microscopy-based connectomics. Nat. Commun. 6:7923. doi: $10.1038 /$ ncomms8923

Huang, S. Y., Nummenmaa, A., Witzel, T., Duval, T., Cohen-Adad, J., Wald, L. L., et al. (2015). The impact of gradient strength on in vivo diffusion MRI estimates of axon diameter. Neuroimage 106, 464-472. doi: 10.1016/j.neuroimage.2014.12.008

Hunter, E. E., Maloney, P., and Bendayan, M. (1993). Practical Electron Microscopy: A Beginner's Illustrated Guide. New York, NY: Cambridge University Press.

Imitola, J., Côt,é, D., Rasmussen, S., Xie, X. S., Liu, Y., Chitnis, T., et al. (2011). Multimodal coherent anti-Stokes Raman scattering microscopy reveals microglia-associated myelin and axonal dysfunction in multiple sclerosis-like lesions in mice. J. Biomed. Opt. 16:021109. doi: 10.1117/1.3533312

Isaacs, J., Mallu, S., and Batchelor, M. (2014). Modification of commercially available image analysis software for semi-automated qualitative analysis of axon regeneration and myelination in the rat sciatic nerve. J. Neurosci. Methods 233, 45-49. doi: 10.1016/j.jneumeth.2014.05.032

Iwaniuk, A. N., Pellis, S. M., and Whishaw, I. Q. (1999). Is digital dexterity really related to corticospinal projections?: a re-analysis of the Heffner and Masterton data set using modern comparative statistics. Behav. Brain Res. 101, 173-187. doi: 10.1016/S0166-4328(98)00151-X

Jacobs, J. M., and Love, S. (1985). Qualitative and quantitative morphology of human sural nerve at different ages. Brain 108, 897-924. doi: 10.1093/brain/108.4.897

Jeronimo, A., Jeronimo, C. A., Rodrigues Filho, O. A., Sanada, L. S., and Fazan, V. P. (2005). Microscopic anatomy of the sural nerve in the postnatal developing rat: a longitudinal and lateral symmetry study. J. Anat. 206, 93-99. doi: 10.1111/j.0021-8782.2005.00368.x

Johannessen, J. V. (1977). Use of paraffin material for electron microscopy. Pathol Апnu. 12(Pt 2), 189-224.

Johansen-Berg, H., and Behrens, T. E. J. (2013). Diffusion MRI: From Quantitative Measurement to In Vivo Neuroanatomy. London: Elsevier Science.

Joosten, E. A., and Gribnau, A. A. (1988). Unmyelinated corticospinal axons in adult rat pyramidal tract. An electron microscopic tracer study. Brain Res. 459, 173-177. doi: 10.1016/0006-8993(88)90300-9

Karnovsky, M. J. (1965). A formaldehyde-glutaraldehyde fixative of high osmolality for use in electron microscopy. J. Cell Biol. 27, 1A-149A.

Köbbert, C., Apps, R., Bechmann, I., Lanciego, J. L., Mey, J., and Thanos, S. (2000). Current concepts in neuroanatomical tracing. Prog. Neurobiol. 62, 327-351. doi: 10.1016/S0301-0082(00)00019-8

Lamberts, R., and Goldsmith, P. C. (1985). Fixation, fine structure and immunostaining for neuropeptides: perfusion versus immersion of the neuroendocrine hypothalamus. J. Histochem. Cytochem. 34, 389-398.

Langford, L. A., and Coggeshall, R. E. (1980). The use of potassium ferricyanide in neural fixation. Anat. Rec. 197, 297-303. doi: 10.1002/ar.1091970304

Langford, L. A., and Coggeshall, R. E. (1981). Unmyelinated axons in the posterior funiculi. Science 211, 176-177. doi: 10.1126/science.7444459

Lassek, A. M., and Rasmussen, G. L. (1940). A comparative fiber and numerical analysis of the pyramidal tract. J. Comp. Neurol. 72, 417-428. doi: $10.1002 /$ cne. 900720209
Laule, C., Leung, E., Lis, D. K., Traboulsee, A. L., Paty, D. W., Mackay, A. L., et al. (2006). Myelin water imaging in multiple sclerosis: quantitative correlations with histopathology. Mult. Scler. 12, 747-753. doi: 10.1177/1352458506070928

Laurent, C., Guérin, M., Frenois, F.-X., Thuries, V., Jalabert, L., Brousset, P., et al. (2013). Whole-slide imaging is a robust alternative to traditional fluorescent microscopy for fluorescence in situ hybridization imaging using break-apart DNA probes. Hum. Pathol. 44, 1544-1555. doi: 10.1016/j.humpath.2012.12.009

Lawrence, D. G., and Kuypers, H. G. (1968). The functional organization of the motor system in the monkey. Brain 91, 1-14. doi: 10.1093/brain/91.1.1

Lee, D. H., and Lee, J. K. (2013). Animal models of axon regeneration after spinal cord injury. Neurosci. Bull. 29, 436-444. doi: 10.1007/s12264-013-1365-4

Leenen, L., Meek, J., and Nieuwenhuys, R. (1982). Unmyelinated fibers in the pyramidal tract of the rat: a new view. Brain Res. 246, 297-301. doi: 10.1016/0006-8993(82)91179-9

Leenen, L. P., Meek, J., Posthuma, P. R., and Nieuwenhuys, R. (1985). A detailed morphometrical analysis of the pyramidal tract of the rat. Brain Res. 359, 65-80. doi: 10.1016/0006-8993(85)91413-1

Lowe, J. S., and Anderson, P. G. (2014). Stevens and Lowe's Human Histology: With Student Consult Online Access. Philadelphia, PA: Elsevier Health Sciences.

Madou, M. J. (2011). From MEMS to Bio-MEMS and Bio-NEMS: Manufacturing Techniques and Applications. Boca Raton, FL: CRC Press.

Mehrer, H., and Stolwijk, N. A. (2009). Heroes and highlights in the history of diffusion. Diffusion Fundamentals 11, 1-32. Available online at: http://nbnresolving.de/urn:nbn:de:bsz:15-qucosa-188591

Mesbah, R., McCane, B., and Mills, S. (2016). "Deep convolutional encoderdecoder for myelin and axon segmentation," in 2016 International Conference on Image and Vision Computing New Zealand (IVCNZ) (Palmerston North), $1-6$.

Meurant, G. (2011). Descending Pathways to the Spinal Cord. Amsterdam: Elsevier Science.

Mikula, S., Binding, J., and Denk, W. (2012). Staining and embedding the whole mouse brain for electron microscopy. Nat. Methods 9, 1198-1201. doi: 10.1038/nmeth.2213

Mikula, S., and Denk, W. (2015). High-resolution whole-brain staining for electron microscopic circuit reconstruction. Nat. Methods 12, 541-546. doi: $10.1038 /$ nmeth.3361

More, H. L., Chen, J., Gibson, E., Donelan, J. M., and Beg, M. F. (2011). A semi-automated method for identifying and measuring myelinated nerve fibers in scanning electron microscope images. J. Neurosci. Methods 201, 149-158. doi: 10.1016/j.jneumeth.2011.07.026

Morrison, J. C., Cork, L. C., Dunkelberger, G. R., Brown, A., and Quigley, H. A. (1990). Aging changes of the rhesus monkey optic nerve. Invest. Ophthalmol. Vis. Sci. 31, 1623-1627.

Mortelliti, A. J., Malmgren, L. T., and Gacek, R. R. (1990). Ultrastructural changes with age in the human superior laryngeal nerve. Arch. Oto-Rhino-Laryngol. Head Neck Surg. 116, 1062-1069. doi: 10.1001/archotol.1990.01870090078013

Nadeau, J. (2012). Introduction to Experimental Biophysics: Biological Methods for Physical Scientists. Boca Raton, FL: CRC Press.

Nakanishi, R., Goto, J., Ezure, H., Motoura, H., Ayabe, S., and Atsumi, T. (2004). Morphometric analyses of axons in the human lateral corticospinal tract: cervical/lumbar level comparision and relation to the ageing process. Okajimas Folia Anat. Jpn. 81, 1-4. doi: 10.2535/ofaj.81.1

Nathan, P. W., and Smith, M. C. (1982). The rubrospinal and central tegmental tracts in man. Brain J. Neurol. 105, 223-269. doi: 10.1093/brain/105.2.223

Nederlof, M., Watanabe, S., Burnip, B., Taylor, D. L., and Critchley-Thorne, R. (2011). High-throughput profiling of tissue and tissue model microarrays: combined transmitted light and 3-color fluorescence digital pathology. J. Pathol. Inform. 2:50. doi: 10.4103/2153-3539.89849

Nout, Y. S., Rosenzweig, E. S., Brock, J. H., Strand, S. C., Moseanko, R., Hawbecker, S., et al. (2012). Animal models of neurologic disorders: a nonhuman primate model of spinal cord injury. Neurotherapeutics 9, 380-392. doi: 10.1007/s13311-012-0114-0

Ohnishi, A., O’brien, P. C., Okazaki, H., and Dyck, P. J. (1976). Morphometry of myelinated fibers of fasciculus gracilis of man (Abstract). J. Neurol. Sci. 27, 163-172. doi: 10.1016/0022-510X(76)90058-7

Palay, S. L., McGee-Russell, S., Gordon, S., and Grillo, M. A. (1962). Fixation of neural tissues for electron microscopy by perfusion with solutions of osmium tetroxide. J. Cell Biol. 12, 385-410. doi: 10.1083/jcb.12.2.385 
Pantanowitz, L., Valenstein, P. N., Evans, A. J., Kaplan, K. J., Pfeifer, J. D., Wilbur, D. C., et al. (2011). Review of the current state of whole slide imaging in pathology. J. Pathol. Inform. 2:36. doi: 10.4103/2153-3539.83746

Park, E., Velumian, A. A., and Fehlings, M. G. (2004). The role of excitotoxicity in secondary mechanisms of spinal cord injury: a review with an emphasis on the implications for white matter degeneration. J. Neurotrauma 21, 754-774. doi: $10.1089 / 0897715041269641$

Peters, A. (1970). "The fixation of central nervous tissue and the analysis of electron micrographs of the neuropil, with special reference to the cerebral cortex," in Contemporary Research Methods in Neuroanatomy, eds Nauta, W. J. H. and S. O. E. Ebbesson (Berlin, Heidelberg: Springer), 56-75. doi: 10.1007/978-3-642-85986-1_4

Potrusil, T., Wenger, C., Glueckert, R., Schrott-Fischer, A., and Rattay, F. (2012). Morphometric classification and spatial organization of spiral ganglion neurons in the human cochlea: consequences for single fiber response to electrical stimulation. Neuroscience 214, 120-135. doi: 10.1016/j.neuroscience.2012.03.033

Ralston, D. D., Milriy, A. M., and Ralston, H. J. (1987). Non-myelinated axons are rare in the medullary pyramids of the macaque monkey. Neurosci. Lett. 73, 215-219. doi: 10.1016/0304-3940(87)90247-3

Rana, S. V. S. (2008). Biotechniques: Theory and Practice. New Delhi: Rastogi Publications.

Reiner, A., Veenman, C. L., Medina, L., Jiao, Y., Del Mar, N., and Honig, M. G. (2000). Pathway tracing using biotinylated dextran amines. J. Neurosci. Methods 103, 23-37. doi: 10.1016/S0165-0270(00)00293-4

Repka, M. X., and Quigley, H. A. (1989). The effect of age on normal human optic nerve fiver number and diameter. Ophthalmology 96, 26-32. doi: 10.1016/S0161-6420(89)32928-9

Reynaud, J., Cull, G., Wang, L., Fortune, B., Gardiner, S., Burgoyne, C. F., et al. (2012). Automated quantification of optic nerve axons in primate glaucomatous and normal eyes-method and comparison to semiautomated manual quantification. Investig. Ophthalmol. Vis. Sci. 53, 2951-2959. doi: $10.1167 /$ iovs.11-9274

Robertson, J. D. (1957). New observations on the ultrastructure of the membranes of frog peripheral nerve fibers. J. Biophys. Biochem. Cytol. 3, 1043-1048. doi: $10.1083 /$ jcb.3.6.1043

Rodrigues, A. R., Ferreira, R. S., Salgado, H. C., and Fazan, V. P. (2011). Morphometric analysis of the phrenic nerve in male and female Wistar-Kyoto (WKY) and spontaneously hypertensive rats (SHR). Brazil. J. Med. Biol. Res. 44, 583-591. doi: 10.1590/S0100-879X2011007500053

Romero, E., Cuisenaire, O., Denef, J. F., Delbeke, J., Macq, B., and Veraart, C. (2000). Automatic morphometry of nerve histological sections. J. Neurosci. Methods 97, 111-122. doi: 10.1016/S0165-0270(00)00167-9

Rossignol, S. (2006). Plasticity of connections underlying locomotor recovery after central and/or peripheral lesions in the adult mammals. Philos. Trans. R. Soc. B Biol. Sci. 361, 1647-1671. doi: 10.1098/rstb.2006.1889

Rushton, W. A. (1951). A theory of the effects of fibre size in medullated nerve. J. Physiol. 115, 101-122. doi: 10.1113/jphysiol.1951.sp004655

Russel, J., and Demyer, W. (1961). The quantitative cortical origin of pyramidal axons of Macaca rhesus, with some remarks on the slow rate of axolysis. Neurology 11, 96-108. doi: 10.1212/WNL.11.2.96

Sandkuijl, D., Kontenis, L., and Barzda, V. (2013). "Super-resolution interferometric third harmonic generation microscopy," in Nonlinear Optics (Kohala Coast).

Schain, A. J., Hill, R. A., and Grutzendler, J. (2014). Label-free in vivo imaging of myelinated axons in health and disease with spectral confocal reflectance microscopy. Nat. Med. 20, 443-449. doi: 10.1038/nm.3495

Schieber, M. H. (2007). Comparative anatomy and physiology of the corticospinal system. Handb. Clin. Neurol. 82, 15-37. doi: 10.1016/S0072-9752(07)80005-4

Schultz, R. L., and Karlsson, U. (2006). Fixation of the central nervous system for electron microscopy by aldehyde perfusion. II. Effect of osmolarity, $\mathrm{pH}$ of perfusate, and fixative concentration. J. Ultrastruct. Res. 12, 187-206. doi: $10.1016 / \mathrm{S} 0022-5320(65) 80015-6$

Sheehan, D. C., and Hrapchak, B. B. (1980). Theory and Practice of Histotechnology. St. Louis: Mosby Incorporated.

Silva, N. A., Sousa, N., Reis, R. L., and Salgado, A. J. (2014). From basics to clinical: a comprehensive review on spinal cord injury. Prog. Neurobiol. 114, 25-57. doi: 10.1016/j.pneurobio.2013.11.002
Soltanpour, N., Asghari Vostacolaee, Y., and Pourghasem, M. (2012). Comparison of morphometric aspects of light and electron microscopy of the hypoglossal nerve between young and aged male wistar rats. Cell J. 13, 229-236. Available online at: http://celljournal.org/journal/article/834/download

Souma, Y., Goto, N., Goto, J., Fujimoto, T., and Fujiwara, T. (2009). Morphological evaluation of the human pyramidal tract: tapering of axons. Okajimas Folia Anat. Jpn. 85, 111-113. doi: 10.2535/ofaj.85.111

Sparks, D. L., Lue, L.-F., Martin, T. A., and Rogers, J. (2000). Neural tract tracing using Di-I: a review and a new method to make fast $\mathrm{Di}$-I faster in human brain. J. Neurosci. Methods 103, 3-10. doi: 10.1016/S0165-0270(00)00291-0

Spence, S. (2009). The Actor's Brain: Exploring the Cognitive Neuroscience of Free Will. Oxford: Oxford University Press.

Srinivasan, V. J., Radhakrishnan, H., Jiang, J. Y., Barry, S., and Cable, A. E. (2012). Optical coherence microscopy for deep tissue imaging of the cerebral cortex with intrinsic contrast. Opt. Express 20, 2220-2239. doi: 10.1364/OE.20.002220

Standring, S. (2008). Gray's Anatomy: The Anatomical Basis of Clinical Practice. London: Elsevier Health Sciences.

Stikov, N., Campbell, J. S. W., Stroh, T., Lavelée, M., Frey, S., Novek, J., et al. (2015). In vivo histology of the myelin g-ratio with magnetic resonance imaging. Neuroimage 118, 397-405. doi: 10.1016/j.neuroimage.2015.05.023

Stikov, N., Perry, L. M., Mezer, A., Rykhlevskaia, E., Wandell, B. A., Pauly, J. M., et al. (2011). Bound pool fractions complement diffusion measures to describe white matter micro and macrostructure. Neuroimage 54, 1112-1121. doi: 10.1016/j.neuroimage.2010.08.068

Tator, C. H., and Fehlings, M. G. (1991). Review of the secondary injury theory of acute spinal cord trauma with emphasis on vascular mechanisms. J. Neurosurg. 75, 15-26. doi: 10.3171/jns.1991.75.1.0015

Terao, S., Sobue, G., Hashizume, Y., Shimada, N., and Mitsuma, T. (1994). Agerelated changes of the myelinated fibers in the human corticospinal tract: a quantitative analysis. Acta Neuropathol. 88, 137-142. doi: 10.1007/BF00294506

Thavarajah, R., Mudimbaimannar, V. K., Elizabeth, J., Rao, U. K., and Ranganathan, K. (2012). Chemical and physical basics of routine formaldehyde fixation. J. Oral Maxillofacial Pathol. 16, 400-405. doi: 10.4103/0973-029X.102496

Thomas, A., Westrum, L. E., Devito, J. L., and Biedenbach, M. A. (1984). Unmyelimated axons in the pyramidal tract of the cat. Brain Res. 301, 162-165. doi: 10.1016/0006-8993(84)90416-5

Tiago, R., Pontes, P., and do Brasil, O. C. (2007). Age-related changes in human laryngeal nerves. Otolaryngol. Head Neck Surg. 136, 747-751. doi: 10.1016/j.otohns.2006.11.054

Towe, A. (1973). Relative numbers of pyramidal tract neurons in mammals of different sizes. Brain Behav. Evol. 7, 1-17. doi: 10.1159/000124395

Towe, A. L., and Luschei, E. S. (2013). Motor Coordination. New York, NY: Springer.

Uk, M., and Al, E. (2006). Clinical Neurophysiology, 2nd Edn. New Delhi: Elsevier. van Crevel, H., and Verhaart, W. J. C. (1963). The rate of secondary degeneration in the central nervous system I. The pyramidal tract of the cat. J. Anat. 97, 429-449.

Vercelli, A., Repici, M., Garbossa, D., and Grimaldi, A. (2000). Recent techniques for tracing pathways in the central nervous system of developing and adult mammals. Brain Res. Bull. 51, 11-28. doi: 10.1016/S0361-9230(99)00229-4

Verhaart, W. J. C. (1947). On thick and thin fibers in the pyramidal tract. Acta Psych. 22, 271-281. doi: 10.1111/j.1600-0447.1947.tb08247.x

Wada, A., Goto, J., Goto, N., Kawamura, N., and Matsumoto, K. (2001). Are there one million nerve fibres in the human medullary pyramid? Okajimas Folia Anat.Jpn. 77, 221-224. doi: 10.2535/ofaj1936.77.6_221

Wagner, C. K., and Clemens, L. G. (1991). Projections of the paraventricular nucleus of the hypothalamus to the sexually dimorphic lumbosacral region of the spinal cord. Brain Res. 539, 254-262. doi: 10.1016/0006-8993(91)91629-F

Wang, C., Popescu, D. C., Wu, C., Zhu, J., Macklin, W., and Wang, Y. (2010). In situ fluorescence imaging of myelination. J. Histochem. Cytochem. 58, 611-621. doi: $10.1369 /$ jhc.2010.954842

Wang, H., Fu, Y., Zickmund, P., Shi, R., and Cheng, J.-X. (2005). Coherent antistokes Raman scattering imaging of axonal myelin in live spinal tissues. Biophys. J. 89, 581-591. doi: 10.1529/biophysj.105.061911

Watanabe, K., Kondo, K., Yamasoba, T., and Kaga, K. (2007). Age-related change in the axonal diameter of the olfactory nerve in mouse lamina propria. Acta Otolaryngol. 127(suppl. 559), 108-112. doi: 10.1080/03655230701597598 
Watson, C., and Harrison, M. (2012). The location of the major ascending and descending spinal cord tracts in all spinal cord segments in the mouse: actual and extrapolated. Anat. Rec. 295, 1692-1697. doi: 10.1002/ar.22549

Watson, C., Paxinos, G., and Kayalioglu, G. (2009). The Spinal Cord: A Christopher and Dana Reeve Foundation Text and Atlas. Amsterdam: Elsevier Science.

Weinstein, R. S., Graham, A. R., Richter, L. C., Barker, G. P., Krupinski, E. A., Lopez, A. M., et al. (2009). Overview of telepathology, virtual microscopy, and whole slide imaging: prospects for the future. Hum. Pathol. 40, 1057-1069. doi: 10.1016/j.humpath.2009.04.006

Williams, T. H., and Jew, J. Y. (1975). An improved method for perfusion fixation of neural tissues for electron microscopy. Tissue Cell 7, 407-418. doi: 10.1016/0040-8166(75)90015-4

Xing, Y., Samuvel, D. J., Stevens, S. M., Dubno, J. R., Schulte, B. A., and Lang, H. (2012). Age-related changes of myelin basic protein in mouse and human auditory nerve. PLoS ONE 7:e34500. doi: 10.1371/journal.pone.0034500

Yang, S., Li, C., Zhang, W., Wang, W., and Tang, Y. (2008). Sex differences in the white matter and myelinated nerve fibers of Long-Evans rats. Brain Res. 1216, 16-23. doi: 10.1016/j.brainres.2008.03.052

Yong-Hing, C. J., Obenaus, A., Stryker, R., Tong, K., and Sarty, G. E. (2005). Magnetic resonance imaging and mathematical modeling of progressive formalin fixation of the human brain. Magn. Reson. Med. 54, 324-332. doi: 10.1002/mrm.20578

Zaimi, A., Duval, T., Gasecka, A., Côté, D., Stikov, N., and CohenAdad, J. (2016). AxonSeg: open source software for axon and myelin segmentation and morphometric analysis. Front. Neuroinform. 10:37. doi: $10.3389 /$ fninf.2016.00037
Zaimi, A., Wabartha, M., Herman, V., Antonsanti, P.-L., Perone, C. S., and CohenAdad, J. (2017). AxonDeepSeg: automatic axon and myelin segmentation from microscopy data using convolutional neural networks. arXiv:1711. 01004.

Zelenin, P. V., Beloozerova, I. N., Sirota, M. G., Orlovsky, G. N., and Deliagina, T. G. (2010). Activity of red nucleus neurons in the cat during postural corrections. J. Neurosci. 30, 14533-14542. doi: 10.1523/JNEUROSCI.2991-10.2010

Zhou, M., Goto, N., Goto, J., Moriyama, H., and He, H. (2000). Gender dimorphism of axons in the human lateral corticospinal tract. Okajimas Folia Anat.Jpn. 77, 21-28. doi: 10.2535/ofaj1936.77.1_21

Zhou, M., Goto, N., Otsuka, N., Moriyama, H., and Nakamura, Y. (1997). Morphometric analyses of axons in the lateral corticospinal tract with ageing process. Okajimas Folia Anat. Jpn. 74, 133-138. doi: 10.2535/ofaj1936.74.4_133

Conflict of Interest Statement: The authors declare that the research was conducted in the absence of any commercial or financial relationships that could be construed as a potential conflict of interest.

Copyright (C) 2017 Saliani, Perraud, Duval, Stikov, Rossignol and Cohen-Adad. This is an open-access article distributed under the terms of the Creative Commons Attribution License (CC BY). The use, distribution or reproduction in other forums is permitted, provided the original author(s) or licensor are credited and that the original publication in this journal is cited, in accordance with accepted academic practice. No use, distribution or reproduction is permitted which does not comply with these terms. 